\title{
The T Cell Receptor/CD3 Complex Is Composed of at Least Two Autonomous Transduction Modules
}

\author{
Anne-Marie K. Wegener, François Letourneur, * \\ Arnd Hoeveler, Thomas Brocker, Frédéric Luton, \\ and Bernard Malissen \\ Centre d'Immunologie \\ INSERM-CNRS de Marseille-Luminy \\ Case 906 \\ 13288 Marseille Cedex 9 \\ France
}

\section{Summary}

Recent studies have demonstrated that the CD3- $\zeta$ subunit of the $T$ cell antigen receptor (TCR) complex is involved in signal transduction. However, the function of the remaining invariant subunits, $\mathrm{CD} 3-\gamma,-\delta$, and $\varepsilon$, is still poorly understood. To examine their role in TCR function, we have constructed TCR/CD3 complexes devoid of functional $\zeta$ subunit and showed that they are still able to trigger the production of interleukin-2 in response to antigen or superantigen. These data, together with previous results, indicate that the TCR/ CD3 complex is composed of at least two parallel transducing units, made of the $\gamma \delta \varepsilon$ and $\zeta$ chains, respectively, Furthermore, the analysis of partially truncated $\zeta$ chains has led us to individualize a functional domain that may have constlituted the building block of most of the transducing subunits associated with antigen receptors and some Fc receptors.

\section{Introduction}

The T cell antigen receptor (TCR) is a multisubunit complex composed of the products of at least six distinct genes. The TCR $\alpha$ and TCR $\beta$ subunits exist as disulfidelinked heterodimers, possess short cytoplasmic tails, and contain clonally variable regions that determine the antigenic specificity of the complex. The remaining subunits, termed CD3- $\gamma,-\delta,-\varepsilon,-\zeta$, and $-\eta$, are invariant, noncovalently associated with the TCR $\alpha \beta$ dimer, and possess large intracytoplasmic domains thought to be responsible for coupling antigen recognition to various signal transduction pathways. The evolutionarily related $\gamma, \delta$, and $\varepsilon$ subunits are expressed as noncovalently associated $\gamma \varepsilon$ and $\delta \varepsilon$ pairs (Koning et al., 1990; Blumberg et al., 1990; De la Herra et al., 1991), and display immunoglobulin-like extracellular domains (Gold et al., 1987). In contrast, the $\zeta$ and $\eta$ subunits contain an extracellular domain of only 9 residues and constitute the prototype of a new protein family that includes the $\gamma$ chain of the high affinity lgE receptor (FcERI) (Weissman etal., 1988; Jin et al., 1990; Küster et al., 1990). When coexpressed in a single $\mathrm{T}$ cell, the $\zeta, \eta$, and FceRly polypeptides can combine to form multiple disulfide-linked

*Present address: Cell Biology and Metabolism Branch, National Institute of Child Health and Human Development, Bethesda, Maryland 20892. homodimers and heterodimers (e.g., $\zeta \zeta, \zeta \eta, \zeta \gamma \ldots$. ), capable of associating with a core made of the $\alpha \beta, \gamma \varepsilon$, and $\delta \varepsilon$ pairs (Orloff et al., 1990). Therefore, several TCR isoforms, made of distinct subunit combinations (e.g., $\alpha \beta \delta \varepsilon \gamma \varepsilon \zeta \zeta$ or $\alpha \beta \delta \varepsilon \gamma \varepsilon \zeta \eta)$, may coexist within a given $T$ cell and be responsible for coupling antigen recognition to distinct signaling pathways (Bauer et al., 1991).

Stimulation of the TCR by antigen, superantigen, or anti-receptor antibodies activates at least two signal transduction pathways (for review see Klausner and Samelson, 1991). The first one, which probably involves the phospholipase $\mathrm{C}_{-} \gamma 1(\mathrm{PCL}-\gamma 1)$, results in the activation of a protein kinase $\mathrm{C}$ and in a rise in intracellular calcium levels. Protein kinase $C$ activation leads to the serine phosphorylation of multiple cellular substrates (e.g., CD3- $y$; Cantrell et al., $1985)$ and causes the rapid activation of secondary signal transducers such as p21 ${ }^{\text {ras }}$ (Downward et al., 1990) and the c-raf kinase (Siegel et al., 1990). The second pathway operates through protein tyrosine kinases (PTKs) and causes the phosphorylation of several substrates including CD3- $\zeta$ (Samelson et al., 1986b) and PLC- $\gamma 1$ (Park et al., 1991; Weiss et al., 1991). Studies of T cell mutants, kinetic analyses, and the use of specific PTK inhibitors suggest that the TCR-driven PTK activation event precedes and is a prerequisite for PLC- $\gamma 1$ activation (Mercép et al., 1988; June et al., 1990; Mustelin et al., 1990). Since none of the CD3 subunits possesses intrinsic PTK activity, it is thought that their intracellular domains associate with one or more cytoplasmic PTKs. Although there are no definitive data on the identity of the TCR/CD3-associated PTK, tyn, a member of the src family of PTK, has been found to coprecipitate with the TCR/CD 3 complex and may represent the kinase responsible for the initiation of the PTK pathway (Klausner and Samelson, 1991).

Several systems have been developed to address the role of individual $\mathrm{CD} 3$ components in T cell activation. For instance, reconstitution of a $\zeta$-deficient $T$ hybridoma with $\zeta$ polypeptides harboring various alterations of the cytoplasmic tail greatly impairs antigen- and superantigeninduced interleukin-2 (IL-2) production (Frank et al., 1990). Further support for the critical role of $\zeta$ in $T$ cell activation has been obtained by the analysis of chimeric transmembrane proteins made of the intracellular domain of the $\zeta$ chain and the extracellular domains of the CD4 or CD8 molecules (Romeo and Seed, 1991; Irving and Weiss, 1991). When expressed independently of the whole TCR/ CD3 complex, antibody-mediated cross-linking of these chimeras has been found to be sufficient to stimulate the PTK pathway and the ensuing biochemical events normally seen upon TCR engagement. These data, together with those indicating that the $\zeta$ dimer may physiologically function outside of the TCR/CD3 context (e.g., in association with the FcyRIII receptor found on natural killer cells; Lanier et al., 1989; Anderson et al., 1989), suggest that one role of $\zeta$ is to couple receptor engagement to intracellular signaling pathways. Furthermore, when considered in view of the results of Frank et al. (1990) (see above), they 
A

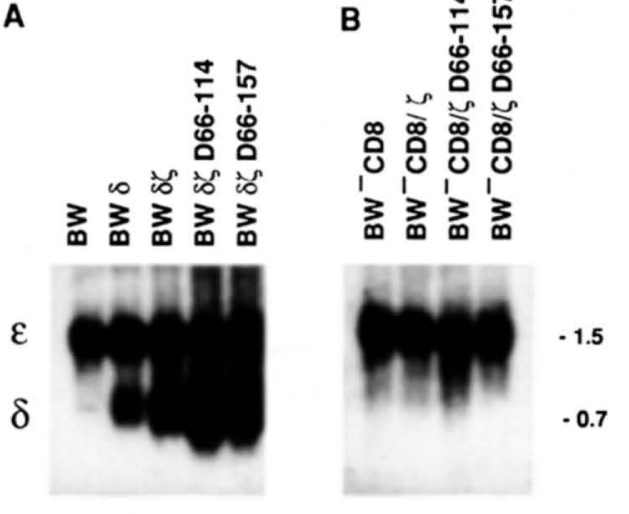

D

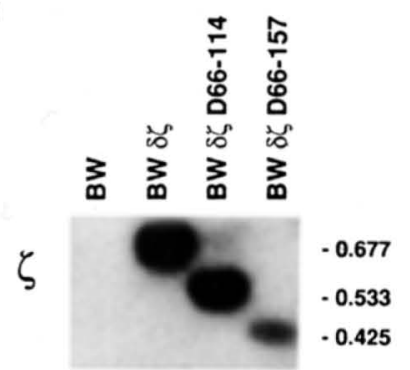

C
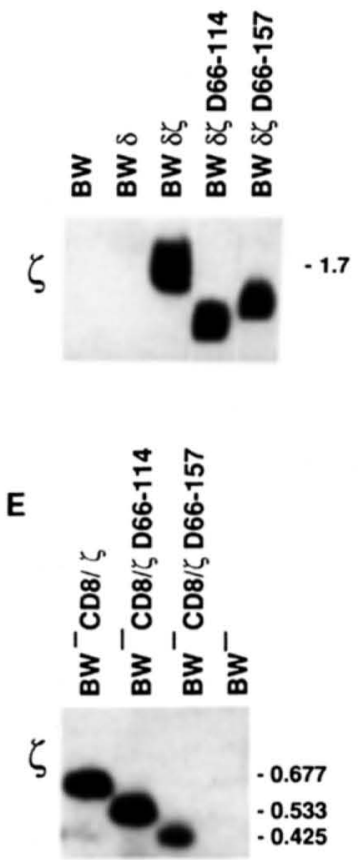

Figure 1. Northern Blot and PCR Analyses of RNA Extracted from the $\mathrm{BW}$ and $\mathrm{BW}$ - Recipient Cell Lines and Their Corresponding CD3- $\delta$,

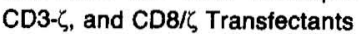

(A-C) Total RNA from the indicated cell lines was size fractionated (10 $\mu \mathrm{g} / \mathrm{lan} \theta)$, transferred to nitrocellulose, and hybridized to probes specific for either CD3- $\delta$ and $-\varepsilon$ (A and $B$ ) or CD3 $\zeta$ (C). The relative sizes (in $\mathrm{kb}$ ) of the bands are indicated in the right margin. Note that the לD66-114 construct lacks a segment of the $3^{\prime}$ untranslated region (see Experimental Procedures) and consequently directs the synthesis of a transcript with a molecular weight ( $1.2 \mathrm{~kb})$ smaller than the one observed for the $\zeta \mathrm{D} 66-157$ construct (1.4 kb).

(D and E) RNA from the indicated cell lines was reverse transcribed with primer $\zeta \mathrm{d}$ (see Experimental Procedures). Subsequent PCR amplification was for 30 cycles using primers $C D 8 / \zeta \mathrm{C}$ and $\zeta \mathrm{d}$ (see Experimental Procedures). The amplified products were run on a $1.7 \%$ agarose gel, transferred to nitrocellulose, and hybridized with a CD3- $\zeta$-specific probe. The size (in $\mathrm{kb}$ ) of the amplified bands is indicated in the margin. have led to the hypothesis that $\gamma, \delta$, and $\varepsilon$ might not constitute coupling subunits but instead modulate TCR function and/or serve as docking structures for molecules such as CD4, CD8, Thy-1, Ly-6, CD45, or CD2 (Irving and Weiss, 1991). To approach the exact role of $\gamma, \delta$, and $\varepsilon$ in the absence of functional $\zeta$ dimers, we have developed a gene transfer system based on the mouse BW5147 thymoma. This system offers the unique possibility to assess in the very same cellular recipient the transducing properties of mutated CD3 subunits expressed either individually or in the context of a whole TCR. We thus show that, in response to activation by antigen or superantigen, TCR/CD3 complexes devoid of functional $\zeta$ subunits can trigger IL-2 production to levels comparable with those obtained with intact complexes. These data, together with those obtained with the CD8/ל chimeras, establish that the TCR/ CD3 complex consists of two autonomous transduction units made of the $\gamma \delta \varepsilon$ and $\zeta$ subunits, respectively. Furthermore, the functional analysis of a CD8/ $/$ chimera involving a partially truncated $\zeta$ chain has allowed us to individualize a structural motif that is repeated three times in the $\zeta$ cytoplasmic tail, and demonstrate that the expression of a single copy of this motif is sufficient to transduce signals leading to substantial IL-2 production. Consistent with the latter observation, similar, and probably evolutionarily related motifs are present, as single copies, in most of the polypeptides associated with antigen receptors or some Fc receptors (FcRs).

\section{Results}

\section{Reconstitution of a Functional TCR Complex in BW5147}

The BW5147 thymoma (hereafter referred to as BW) expresses transcripts hybridizing to TCR $\alpha-$, TCR $\beta-$, CD3 $\gamma-$, and CD3- $\varepsilon$-specific probes but lacks those corresponding to the CD3- $\delta$ and CD3- $\zeta$ genes (Figures $1 A, 1 C$, and 1D; Letourneur and Malissen, 1989). These results agree with previous biosynthetic analyses (Bonifacino et al., 1988), and explain the absence of detectable TCR at the surface of BW (Figure 2). Because the structually related CD3- $\eta$ and FceRI- $\gamma$ subunits can in some instances substi-

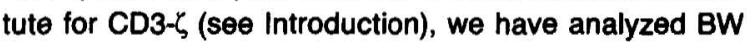
for the products of these genes and found that neither could be detected by polymerase chain reaction (PCR; data not shown).

To reconstitute the expression of TCR complexes at the surface of BW, plasmids containing wild-type $\delta$ and $\zeta$ genes were sequentially transfected into BW. As shown in Figures $1 \mathrm{~A}$ and $1 \mathrm{C}$, Northern blot analysis of a representa-

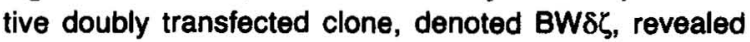
the presence of abundant transcripts corresponding to the introduced $\delta$ and $\zeta$ genes. Furthermore, coexpression of $\delta$ and $\zeta$ in BW readily restores the surface expression of TCR complexes (Figure 2), which display a proper subunit composition when analyzed by two-dimensional (2D) SDS-PAGE (Figure 3A, compare panels BW and BW $\delta \zeta$ ).

To determine whether the reexpressed TCR can transduce signals leading to IL-2 production, the BWSC cells were first stimulated with the anti-CD3- $\varepsilon$ monoclonal antibody (MAb) 2C11 bound to the surface of the FCR-positive $B$ cell lymphoma LK. In contrast to the situation observed for the parental BW cells, stimulation with the cross-linked

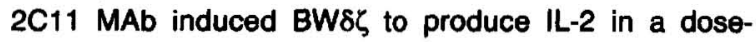
dependent manner (Figure 4A). However, since recent evidence suggests that there are some distinctions between the coupling mechanisms observed upon stimulation with physiologic ligands or anti-CD3 MAb (Frank et al., 1990),

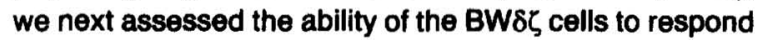
to superantigenic and antigenic challenges. The TCR $\beta$ 


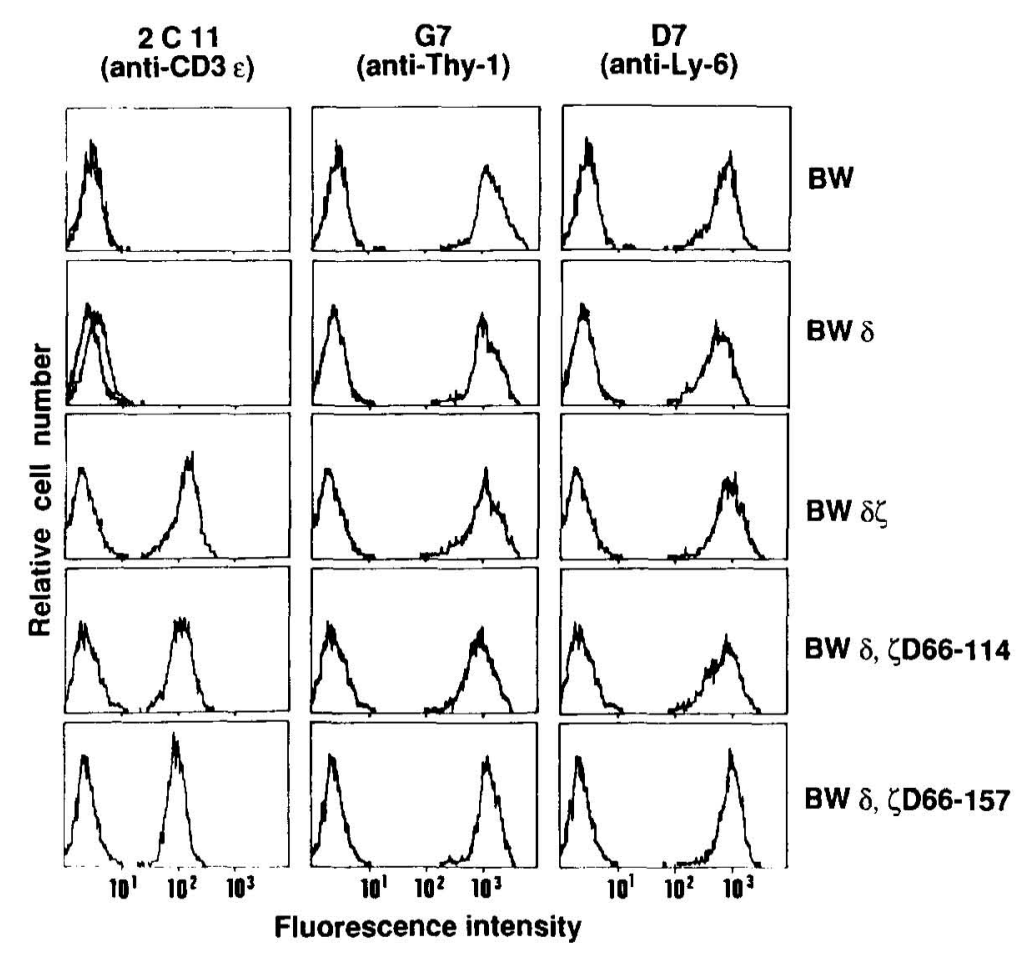

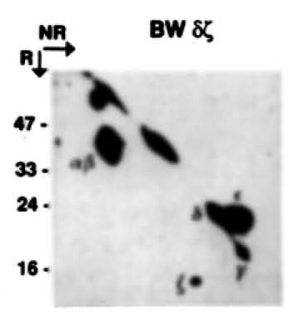

C

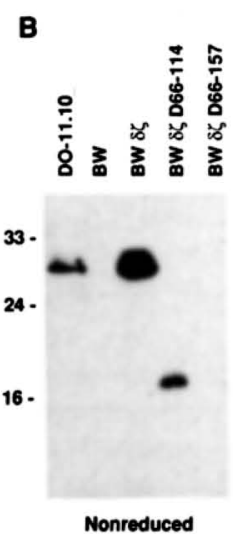

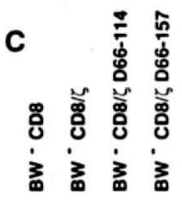

Reduced
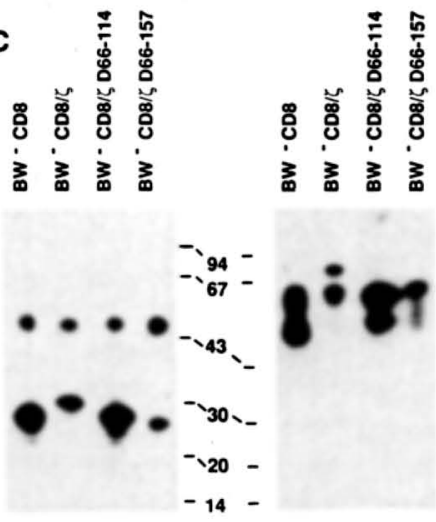

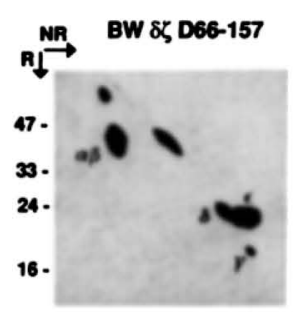

$\frac{5}{5}$

Figure 2. Expression of the TCR/CD3 Complex at the Surface of the BW Cells Following Sequential Transfer of the CD3- $\delta$ Gene and of

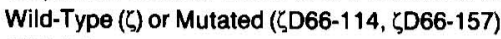
CD3- $\zeta$ Genes

The parental and transfected cell lines were analyzed by flow cytometry after staining with the anti-CD3- $\varepsilon$ antibody $2 C 11$, the anti-Thy-1 antibody G7, or the anti-Ly6 antibody D7. Each fluorescence histogram is compared with a negative control histogram obtained after staining with a rat anti-mouse lgG3 antibody.

Figure 3. Immunoprecipitation and Immunoblotting Analyses of the CD3- $\zeta$ and $C D 8 / \zeta$ Polypeptides Expressed by the $\mathrm{BW}$ or $\mathrm{BW}$ Transfectants

(A) 2D (nonreducing/reducing) electrophoresis of TCR/CD3 chains precipitated by the $2 \mathrm{C} 11$ (anti-CD3- $\varepsilon$ ) antibody from lysates of surface-

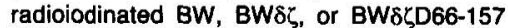
cells. The positions of the various TCP/CD3 chains are indicated.

(B) Identification of the $(\zeta)_{2}$ and $(\zeta D 66-114)_{2}$ homodimers. Lysates from the indicated cell lines were immunoprecipitated with the $2 \mathrm{C}+1$ antibody. Immunoprecipitates were analyzed on nonreducing SDS-polyacrylamide gels and immunoblotted with an anti- $\zeta$ serum raised against a peptide corresponding to amino acids 132-144.

(C) Analysis of the CD8 molecule and CD85 chimeras expressed at the surface of the BWtransfectants. Surface-radioiodinated cells were lysed in $0.5 \%$ Triton $X-100$, immunoprecipitated with the 19/178 (anti-CD8- $\alpha$ ) antibody, and analyzed under reducing and nonreducing SDS-polyacrylamide gel electrophoresis. The relative positions of the molecular weight standards are indicated (kd). The $\sim 45 \mathrm{kd}$ band found in each of the $19 / 178$ immunoprecipitates run under reducing conditions (left panel) appears nonspecific, as it is seen after immunoprecipitation with an irrelevant antibody (data not shown). chain reexpressed at the surface of the BWS $\zeta$ cells involves the $V \beta 1$ gene segment product (Letourneur and Malissen, 1989), and should endow them with the capacity to respond to the staphylococcal enterotoxin A (SEA, a superantigen that stimulates $T$ cells in a V $B$-specific and major histocompatibility complex class II-restricted man- ner; Herman et al., 1990). As shown in Figure 4B, the BW $\delta \zeta$ cells react vigorously to SEA presented by HLADR1-positive cells. It should be noted at this point that even the minute amount of $\zeta$-deficient TCR complexes expressed at the surface of the BW $\delta$ single transfectant (see Figure 2) is able to trigger a weak but significant IL-2 


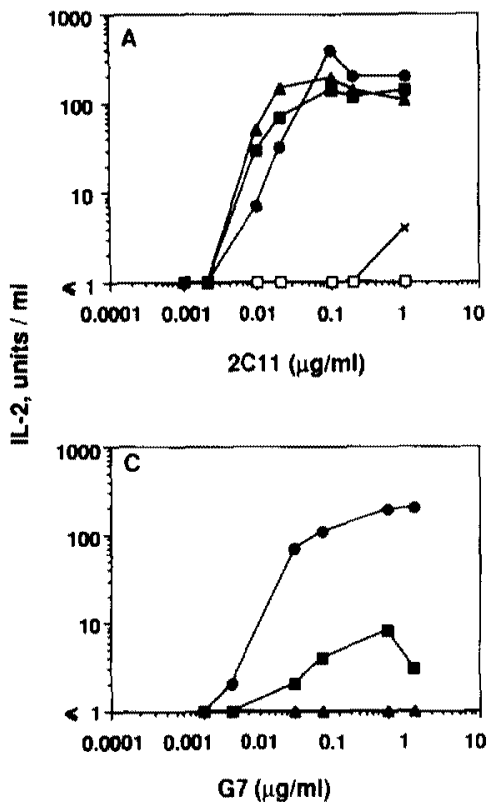

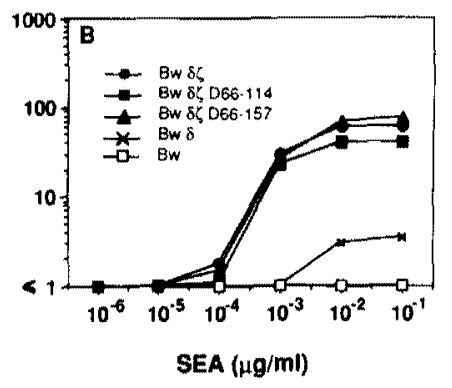

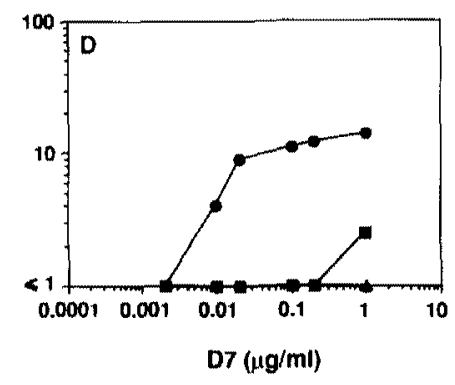

Figure 4. H-2 Production of BW Ceils Transfected with $\mathrm{CD} 3-\delta$ and Various CD3- $\zeta$ Gene Constructs in Response to Stimulation with SEA or Antibodies Directed to the CD3-E (2C11), Thy-1 (G7), or Ly-6 (D7) molecules Approximately $10^{5} \mathrm{BW}$ (open squares), BW ("exes"), 8W8\% (closed circles), BW85D66-114

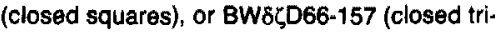
angles) cells were incubated with the indicated concentrations of (A) $2 \mathrm{C} 11$ antibody and $3 \times$ $10^{4} L K$ cells, (B) SEA and $10^{5}$ DR1 $1^{+} L$ cells, (C) G7 antibody and $3 \times 10^{4}$ LK cells, or (D) D7 antibody and $3 \times 10^{4} \mathrm{LK}$ cells. After $24 \mathrm{hr}$, supernatants were assayed for IL.2 content. A concentration of $1 \mathrm{U} / \mathrm{ml}$ of $11-2$ was the minimum detectable in our assay. production in response to either 2C11 or SEA (Figures 4A and 48 ). To circumvent the lack of information concerning the genuine antigenic specificity of the endogeneous BW TCR and gauge antigen responsiveness, we have supertransfected the BW $\zeta \zeta$ cells with the TCR $\alpha$ and $\beta$ chain genes originating from the 2B4 hybridoma (Samelson et al., 1983) and borne by the same plasmid. As summarized in Table 1, the 2B4 TCR molecules detected at the surface of the BW8L/2B4TCR triple transfectant can be activated to trigger IL-2 production as the result of the specific recognition of the pigeon cytochrome $c$ fragment 81-104 (PCC 81-104) bound to $\mathrm{H}-2 \mathrm{E}^{k}$ molecules.

In addition to the TCR/CD3 complex, $T$ cell activation can also be initiated through a number of alternative receptors including Thy- 1 and $L y-6$ in the mouse and CD2 in the human. The operation of these alternative activation pathways depends on the presence of functional TCR/ CD3 complexes on the surface of the T cell (Sussman et al., 1988). Indirect immunofluorescence indicates that the
$B W, B W \delta$, and BW $\delta \zeta$ cells stained brightly and with similar fluorescence intensities with MAb directed against Thy-1 (G7) or Ly-6 (D7) molecules (see Figure 2). Moreover, as shown in Figure $4 C$, the $B W$ and $B W \delta$ cells failed to produce IL-2 at any concentration of G7 or D7 tested. In contrast, culture of BW $\delta \zeta$ with $\mathrm{G} 7$ yielded IL-2 in an antibody dose-dependent fashion. Although less effective than $2 \mathrm{C} 11$ and $\mathrm{G7}$, stimulation of BW8 $\zeta$ with D7 also results in IL-2 production (Figure 4D). Therefore, based on the above observations, once transfected with the $\delta$ gene the BW thymoma should constitute an appropriate recipient to measure the transducing properties of TCR/CD $3 \mathrm{com}$ plexes devoid of functional $\zeta$ subunit.

\section{The Cytoplasmic Tail of the $\zeta$ Polypeptide is Dispensable for Antigenic and Superantigenic Responsiveness}

The mature $\zeta$ protein consists of a 9 amino acid extracellular segment, a 21 amino acid transmembrane segment

Table 1. IL-2 Secretion of Cells Transfected with the 2B4 TCR Genes, in Response to Stimulation with Antigen-Presenting Cells in the Presence and Absence of PCC

\begin{tabular}{|c|c|c|c|c|c|c|c|c|}
\hline \multirow{2}{*}{\multicolumn{3}{|c|}{ Transfected Responder Cells }} & \multicolumn{4}{|c|}{$\begin{array}{l}\text { Relative Fluorescence Intensities after } \\
\text { Staining with Antibodies Specific for: }\end{array}$} & \multicolumn{2}{|c|}{$\begin{array}{l}\mathrm{IL}-2 \text { Secreted }(\mathrm{U} / \mathrm{ml}) \text { in } \\
\text { Response to C3H Splenocytes }\end{array}$} \\
\hline & & & \multirow{2}{*}{$\begin{array}{l}\mathrm{H} 139 \\
(\operatorname{lgG} 3)\end{array}$} & \multirow{2}{*}{$\begin{array}{l}\mathrm{CD} 3 \varepsilon \\
(2 \mathrm{C} 11)\end{array}$} & \multirow{2}{*}{$\begin{array}{l}2 B 4 \text { TCA } \alpha \\
(\mathrm{A} 2 \mathrm{~B} 4-2)\end{array}$} & \multirow{2}{*}{$\begin{array}{l}\text { VB3 } \\
(K J-25)\end{array}$} & \multirow{2}{*}{$\begin{array}{l}\text { Minus } \\
\text { PCC 81-104 }\end{array}$} & \multirow{2}{*}{$\begin{array}{l}\text { Plus } \\
\text { PCC } 81-104\end{array}$} \\
\hline Name & Parental Ceils & Transfected Genes & & & & & & \\
\hline BWÉ & BW & $\mathrm{CD} 38, \mathrm{CD} 3 \zeta$ & 120 & 558 & 123 & 118 & $<1$ & $<1$ \\
\hline BW8 ל̧D66-114 & BW & $\mathrm{CD} 3 \delta, C D 3, D 66-114$ & 134 & 533 & 130 & 126 & $\ll 1$ & $<1$ \\
\hline BW8ร,D66-157 & BW & CD38, CD3ร,D66-157 & 128 & 494 & 119 & 120 & $<1$ & $<1$ \\
\hline BW8Y/2B4 TCR & BW $\delta \zeta$ & $2 B 4$ TCR & 181 & 508 & 418 & 368 & $<1$ & 34 \\
\hline BW8కD66-114/2B4 TCA & BW8ל̧D66-114 & 2B4 TCR & 165 & 573 & 476 & 412 & $<1$ & 17 \\
\hline 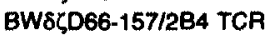 & 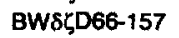 & 2B4 TCR & 201 & 445 & 410 & 301 & $<1$ & 52 \\
\hline
\end{tabular}

Transfected cells $\left(10^{5}\right)$ were cultured with $\mathrm{C} 3 \mathrm{H}\left(\mathrm{E}^{\mathrm{k}}\right.$-positive spenocytes, $\left.10^{8}\right)$ in the absence or presence of a PCC peptide corresponding to amino acids 88-104 (PCC 8t-104, $15 \mu \mathrm{M}$ ). Cultures were for $24 \mathrm{hr}$, at which time supernatants were collected and tested for IL-2. All transfected cells showed similar bright staining with the anti-CD $3 E$ MAb 2C11. The expression of the 2B4 TCR at the surface of the various transfectants was monitored by flow cytometry using a MAb specific for the 2B4 $\alpha$ (A2B4-2) and 2B4 $\beta$ (KJ-25) TCR chains. Background fluorescence levels are given after staining with an anti-mouse lgG3 MAb (H139). 
A

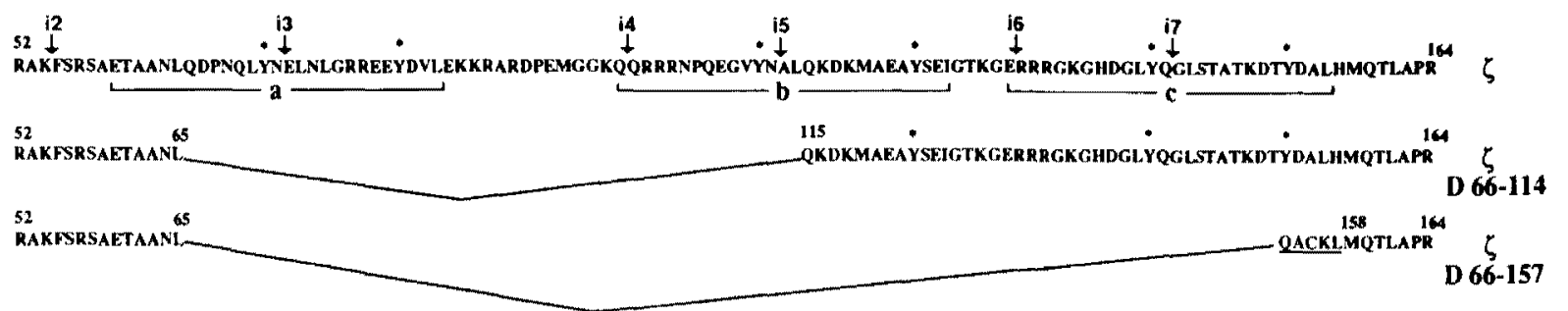

B
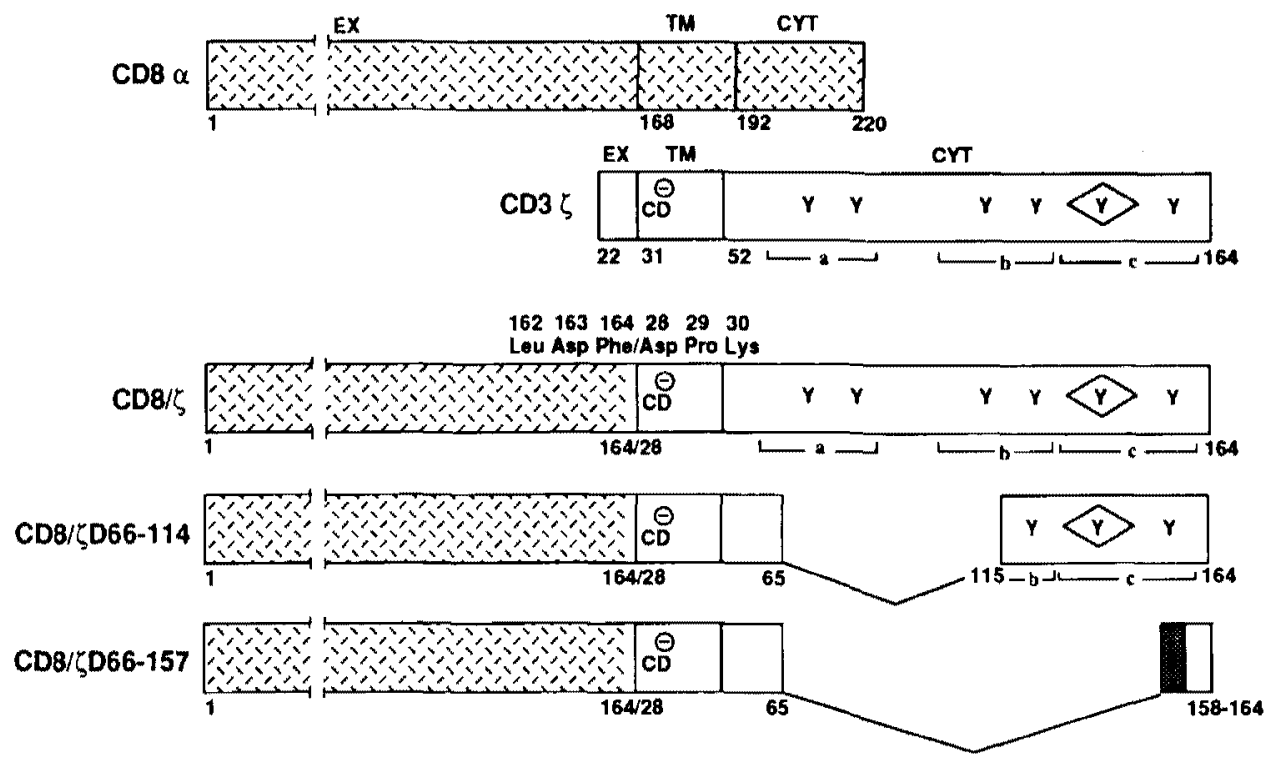

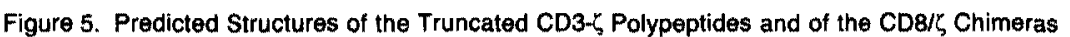

(A) The sequence of the wild-type $\operatorname{CD} 3 \zeta(\zeta)$ cytoplasmic tail is shown in the single-letter amino acid code. The tyrosine residues (asterisks), the position of the introns (i2 to in) in the corresponding gene segment, and the localization of three repeated sequence motifs (a, b, and c; see Figure 9 and Discussion) are highlighted. The sequences of the two CD3- $\zeta$ truncated molecules, $\zeta$ D66-114 and $\zeta$ D66-157, are indicated under the wild-type

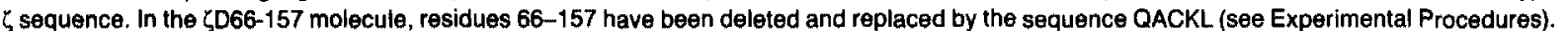
The $\mathrm{CD} 3 \zeta$ residues are numbered according to Weissman et al. (1988).

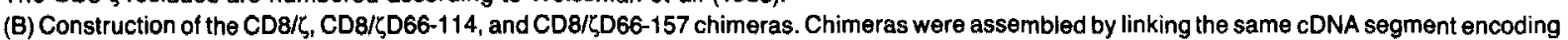
the extracellular (EX) region of CD\& $\alpha$ to the sequences corresponding to the transmembrane (TM) and cytoplasmic (CYT) regions of the CD3- $\zeta_{2}$,

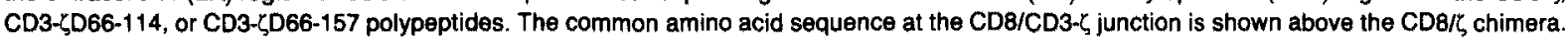
The number above each residue refers to its position in the wild-type sequence (numbering according to Zamoyska et al. [1985] and Weissman et al. [1988]). The cysteine (C) residue involved in the dimerization of the $\zeta$ chain and the aspartic acid (D-) residues found in the CD3- $\zeta$ TM segment are indicated. Also shown are a putative nucleotide-binding site (open diamonds), the tyrosine ( $Y$ ) residues, and the positions of three repeated sequence motifs ( $a, b$, and $c$; see above). The hatched segment shown in the CDB/CD66-157 chimera corresponds to the QACKL sequence.

harboring a negatively charged aspartic acid residue, and a 112 amino acid cytoplasmic tail (Weissman et al., 1988). Two mutated $\zeta$ cDNA constructs were developed with the aim of inactivating the whole or part of the transducing properties of $\zeta$ (see Experimental Procedures). The first one, denoted $\zeta \mathrm{D} 66-114$, corresponds to an internal deletion, in which residues $66-114$ have been removed. As shown in Figure 5, this alteration removes 3 out of 6 tyrosine residues found in the wild-type chain. In the second one, denoted $\zeta \mathrm{D} 66-157$, most of the cytoplasmic domain has been removed (Figure 5). Based on the work of Irving and Weiss (1991), the latter construct, which lacks the six tyrosine residues as well as a putative nucleotide-binding site (Figure 5), should direct the synthesis of a transduction-defective $\zeta$ peptide.

The two constructs were separately introduced into the
BW $\delta$ primary transfectant to create the cell lines BW $\delta \zeta$ D66-114 and BW 85666-157. Northern blot and PCR analyses show that both constructs direct the synthesis of mRNA of the predicted size (see Figures 1C and 1D). Moreover, owing to the size differences existing between the wild-type and truncated $\zeta$ mRNAs, these analyses formally establish that transfection has not derepressed the endogeneous $\zeta$ chain genes that are still present in BW. As shown in Figure 2, both truncated $\zeta$ subunits were able to reconstitute TCR surface expression. Examination of a number of independent clones showed that the surface expression of TCR harboring truncated $\zeta$ subunits was reduced on the average to half the levels observed with wild-type TCR, and further permitted the isolation of clones expressing comparable levels of TCR containing either wild-type or truncated $\zeta$ molecules (see Figure 2). 
To characterize the structure of the mutated $\zeta$ chains, the various $\zeta$ transfectants were lysed in $0.5 \%$ Triton $X-100$ and subjected to immunoprecipitation with the anti-CD3 $\varepsilon$ MAb 2C11. Immunoprecipitates were separated on nonreducing SDS gels and immunoblotted with an anti- $\zeta$ serum raised against a peptide corresponding to amino acids 132-144 (Orloff et al., 1989). As expected, the wild-type BW8, transfectant produced a 32 kd dimer, whereas the ל̧D66-114 dimers migrate at a position slightly above $16 \mathrm{kd}$ (see Figure $3 \mathrm{~B}$ ). In addition, the immunoblotting verified the absence of $\eta$ and the expected lack of immunoreactive

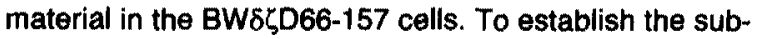
unit composition of the TCR expressed on the surface of BW8ל,D66-157, the corresponding cells were iodinated, lysed in the presence of $0.5 \%$ Triton X-100, and immunoprecipitated with the $2 \mathrm{C} 11 \mathrm{MAb}$. Immunoprecipitates were then analyzed in a $2 \mathrm{D}$ nonreducing/reducing gel. As shown in Figure 3A, the TCR $\alpha \beta$ heterodimer, as well as the CD $3-\gamma,-\delta$, and $-\varepsilon$ subunits are properly expressed in

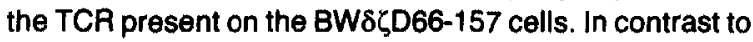
the $16 \mathrm{kd} \zeta$ product found in $B W \delta \zeta$ cells (see Figure $3 \mathrm{~A}$, middle panel), the $\zeta$ D66-157 polypeptide lacks tyrosine residue (Figure 5A) and was therefore not detected in this analysis. However, $2 D$ analysis of the same TCR complexes metabolically labeled with ${ }^{35}$ S]cysteine plus $\left[{ }^{35}\right.$ S]methionine revealed the presence of a unique disulfide-linked dimer of $\sim 8 \mathrm{kd}$ (P. Moingeon, F. L., B. M., and E. Reinherz, unpublished data), consistent with it being the TCR-associated $\zeta$ D66-157 polypeptide. Therefore, we conclude that the deletion of most of the $\zeta$ cytoplasmic segment does not affect measurably the proper assembly and surface expression of the TCR/CD3 complex.

To determine the functional effects of the two deletions,

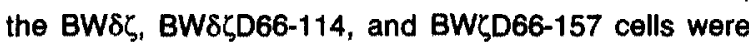
analyzed in parallel for their ability to respond to the antiCD3- $\varepsilon$ MAb $2 \mathrm{C} 11$ and to SEA presented by HLA-DR1positive cells. As shown in Figures $4 A$ and $4 B$, the

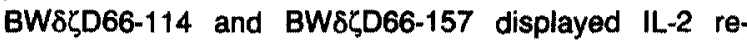

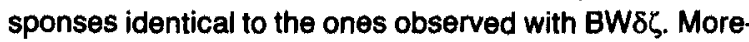
over, once supertransfected with the 2B4-TCR, both

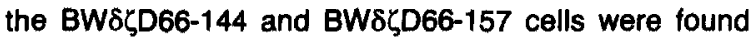
capable of mounting substantial antigenic responses. In marked contrast, and despite the presence of levels of Thy-1 and Ly-6 molecules identical to BW $\delta$ (see Figure 2), the transfectants harboring mutated $\zeta$ chains were found

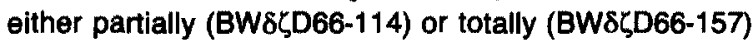
impaired in their ability to respond to anti-Thy-1 (G7) or anti-Ly-6 (D7) MAb (see Figures 4C and 4D). Finally, it should be noted that antibody-mediated cross-linking of the TCR/CD3 complexes expressed at the surface of the

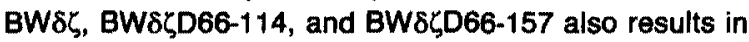
cell cycle arrest as measured by a dramatic reduction in thymidine incorporation (data not shown).

\section{The TCR is Composed of Two Autonomous Transduction Units}

The fact that the BW8ל,D66-157 cells respond effectively to TCR engagement suggests either of the following alternatives. First, the $\gamma, \delta$, and $\varepsilon$ subunits may be sufficient to transduce a signal for IL-2 production. Second, the $\zeta$ D66157 polypeptide may not be totally defective and may still be able to signal through its transmembrane segment and or the few amino acid residues left in its cytoplasmic tail (Figure 5A). To sort out these possibilities, and as pioneered by two recent reports (Irving and Weiss, 1991; Romeo and Seed, 1991), a set of CD8/ל chimeras was constructed and assessed for their relative transducing abilities independently of $\gamma, \delta$, and $\varepsilon$. As summarized in Figure 5B, the $\zeta$, $\zeta \mathrm{D} 66-114$, and $\zeta \mathrm{D} 66-157$ cDNAs were separately fused a few residues upstream of their membrane-spanning domain with the mouse CD8- $\alpha$ extracellular domain (Figure 5B), giving the chimeric products

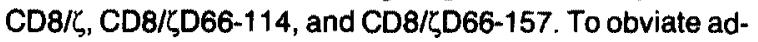
ventitious interactions of the chimeric polypeptides with other TCR/CD3 components, the chimeras were expressed in the BW5147 $\alpha^{-} \beta^{-}$thymoma (hereafter referred to as $\left.\mathrm{BW}^{-}\right) \mathrm{BW}^{-}$is a derivative of $\mathrm{BW}$ that fails to express the TCR $\alpha, \beta$ (White et al., 1989; Letourneur and Malissen, 1989), CD3- $\gamma,-\delta,-\zeta / \eta$, and FceRl- $\gamma$ genes (see Figures $1 \mathrm{~B}$ and $1 \mathrm{E}$; data not shown). In contrast, $\mathrm{BW}^{-}$expresses substantial levels of CD3- $\varepsilon$ transcripts (see Figure 1B). A transfectant expressing the CD8 wild-type molecule, $B W^{-} \mathrm{CD} 8$, was developed in parallel and used to evaluate the possible contribution of the CD8 segment present in the CD8/ל chimeras. PCR analysis of the mRNAs expressed by the $\mathrm{BW}^{-} \mathrm{CD} / / \zeta, \mathrm{BW}^{-} \mathrm{CD} 8 / \zeta 66-114$, and $\mathrm{BW} C \mathrm{CD} 8 / \mathrm{C}_{66-157}$ stable transfectants revealed the presence of correctly sized amplification products (see Figure 1E). When analyzed by cytofluorometry, the chimeric proteins were detected at comparable levels at the cell surface and found unable to associate with and rescue the surface expression of endogeneous $\varepsilon$ chains (Figure 6). However, since the 2C11 MAb used to detect the $\varepsilon$ chains binds an $\theta$ pitope that may require interaction of the $\varepsilon$ chain with either $\gamma$ or $\delta$ (Bonifacino et al., 1989), we have confirmed, using a different approach, that the various chimeric proteins were expressed independently of the endogeneous $\varepsilon$ chains found in BW-. Accordingly, the various transfectants were surface iodinated, lysed in $0.5 \%$ Triton $X-100$ to preserve potential noncovalent protein interactions (see Figure $3 A$ ), and subjected to immunoprecipitation with an anti-CD8 MAb. As shown in Figure $3 \mathrm{C}$, this analysis fails to detect evidence for an association between the various chimeras and the remaining $\varepsilon$ chains (a rationale for this lack of association may be found in that both $\zeta$ and $\varepsilon$ display a positively charged aspartic acid residue in their transmembrane domain; Cosson et al., 1991). Two additional points should be made. First, under reducing conditions, the three chimeric proteins were found to migrate as single bands with molecular weights consistent with their predicted sequences, and the presence of glycosylation sites within the CD8 extracellular domain. Second, and as previously observed for the human CD8/ל chimera (Irving and Weiss, 1991), analysis under nonreducing conditions indicates that each chimera is expressed as disulfide-bonded dimers and/or trimers.

Having characterized the individual chimeric proteins, we next assessed their ability to trigger IL-2 production in response to the anti-CD8 MAb 19/178 precoated on the 


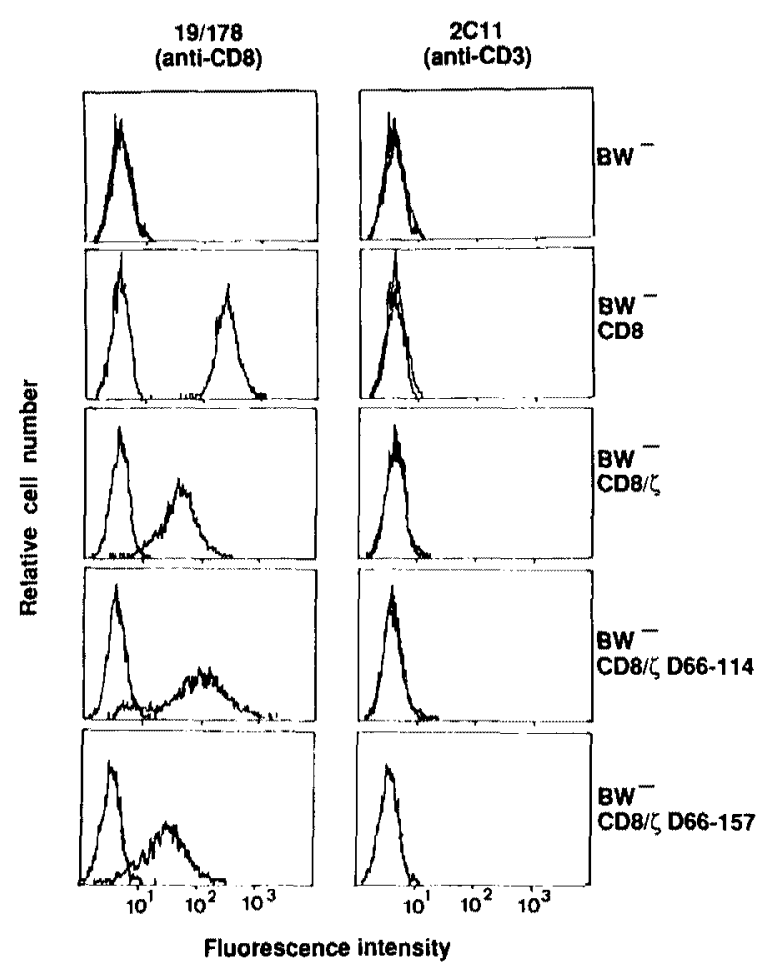

Figure 6. Expression of the CD8 Epitope at the Surface of BW Cells Following Transfection of the CD8 (BW-CD8), $C D 8 / \zeta\left(B W^{-} C D 8 / C\right)$,

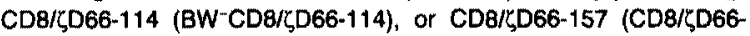
157) Gene Constructs

The parental and transfected cell lines were analyzed by flow cytometry after staining with the anti-CD8- $\alpha$ antibody $19 / 178$ or the anti-CD3 antibody $2 \mathrm{C11}$. Each panel is compared with a negative control histogram obtained after staining with a rat anti-mouse IgG3 antibody.

wells of microtiter plates. As shown in Figure 7A, both $\mathrm{CD8} / \zeta$ and $C D 8 / \zeta \mathrm{D} 66-114$ are capable of delivering a transmembrane signal. If one compares the concentrations of 19/178 MAb required to achieve the production of $10 \mathrm{U}$ of IL-2, CD8/לD66-114 appears about 100-fold less sensitive than $\mathrm{CD} 8 / \zeta$. In contrast, the wild-type CD8 molecule, and more interestingly, the CD8/CD66-157 chimera were unable to induce any detectable IL-2 production.
Note that all the transfectants were capable of IL-2 production in response to the addition of phorbol 12-myristate 13-acetate and ionomycin (data not shown). The lack of function of the tailless CD8//D66-157 chimera is consistent with previous work (Irving and Weiss, 1991; Romeo and Seed, 1991), and formally establishes that the transducing properties of the CD8/ $/ \zeta$ and CD8/ל,D66-114 molecules could not be attributed to the presence of the transmembrane segment or the few residues left in the לD66-157 peptide. Finally, the culture of the various transfectants on microtiter plates coated with the anti-CD3 $\varepsilon \mathrm{MAb} 2 \mathrm{C} 11$ failed to induce any detectable IL-2 production and indicated that none of the transfectants produces constitutive levels of IL-2 (Figure 7B). These data suggest by inference that $\zeta \mathrm{D} 66-157$ is totally defective in terms of coupling to IL-2 production, but is still able to rescue the surface expression of $\alpha \beta \gamma \varepsilon \delta \varepsilon$ complexes capable of triggering levels of IL-2 production comparable with those obtained with intact $\alpha \beta \gamma \varepsilon \delta \varepsilon \zeta \zeta$ complexes.

\section{Discussion}

The work presented here demonstrates that TCR/CD3 complexes harboring transduction-defective $\zeta$ dimers are still able to trigger the production of IL-2 in response to anti-CD3 MAb, antigen, or superantigen. These data, together with those obtained with $\mathrm{CD} 8 / \zeta$ chimeras (Irving and Weiss, 1991; Romeo and Seed, 1991; this paper), suggest that the TCR/CD3 complex is composed of two dissociable functional units referred to as transduction modules and made of the $\gamma \delta \varepsilon$ and $\zeta$ subunits, respectively (Figure 8). Once isolated, each of these modules behaves in an autonomous way and has the property to trigger a late activation event such as IL-2 production. However, the two modules are not fully permutable and each appears endowed with unique characteristics. For instance, and as suggested by the analysis of the BW\$CD66-157 cells, the $\gamma \delta \varepsilon$ module is unable to substitute for $\zeta$ in order to sustain activation initiated via the Thy-1, Ly-6, and CD2 molecules (this paper; P. Moingeon, F. L., B. M., and E. Reinherz, unpublished data). Three additional points should be made. First, the ability of each module to function indepen-
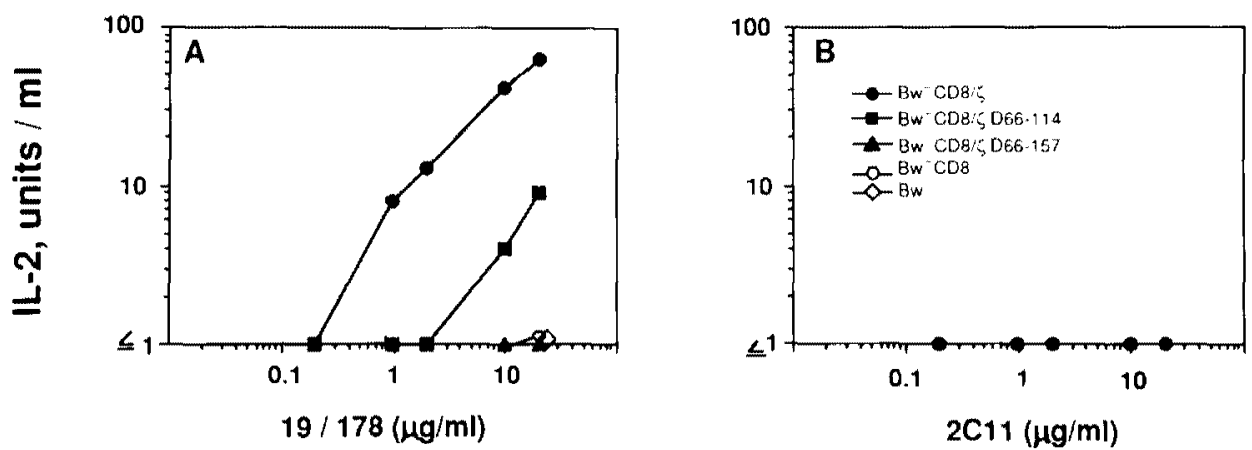

Figure 7. IL-2 Production of BW- Cells Transfected with COB or Various CDB/\% Chimeras in Response to Stimulation with Antibodies Directed to the CD8- $\alpha$ (19/178) or CD3-E (2C11) Molecules

Approximately $10^{5} \mathrm{BW}^{-}$(open diamonds), BW CDB (open circles), BW CDB/ל (closed circles), BW CD8/לD66-114 (closed squares), or BW CD8/ $\zeta$ D66-157 (closed triangles) were cultured in microtiter wells coated with the indicated concentrations of purified (A) 19/178 or (B) 2C11 antibodies. After $24 \mathrm{hr}$, supernatants were assayed for IL-2 content. A concentration of $1 \mathrm{U} / \mathrm{ml}$ of $1 \mathrm{l}-2$ was the minimum detectable in our assay. 


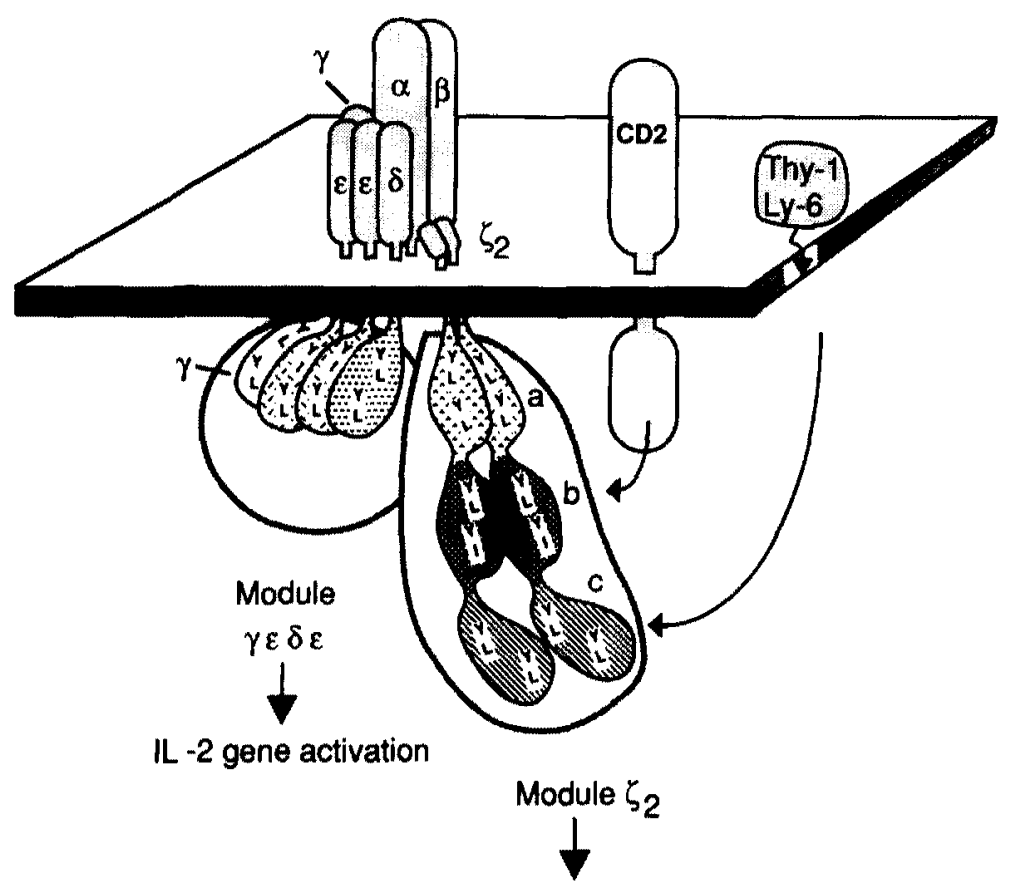

IL -2 gene activation
Figure 8. Minimal Model of the TCR/CD3 Complex Highlighting the Presence of at Least Two Dissociable Transduction Modules Composed of the $\gamma \delta \varepsilon$ and $\zeta$ Subunits, Respectively Each module is capable of transducing parallel signals that result in II-2 gene activation. Based

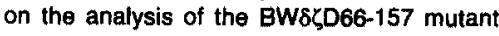
cells, the Thy-1, Ly-6, and CD2 alternative activation pathways have been depicted to branch exclusively on the $\zeta$ module (connecting arrows). The arbitrary representation adopted for the cytoplasmic tail of the various $\mathrm{CD} 3$ subunits aims at highlighting the presence of repeats of a functional motif (see Discussion and Figures 5 and 9). It should be noted that the exact number of modules existing per TCR is unknown. The present estimate is based on the assumption that the TCR/CD 3 complex is made of four dimers: $\alpha \beta, \gamma \varepsilon, \delta \varepsilon$, and $\zeta \zeta$ (Koning et al., 1990; but se日 Manolios et al., 1991: Green, 1991; and Finkel et al., 1991 for other possible subunit combinations). Further work may also break the $\gamma \delta \varepsilon$ "unit" into two functional modules made of $\gamma \varepsilon$ and $\delta \varepsilon$. However, neither the above considerations on the exact stoichiometry of the TCR subunits nor the probable occurrence of TCR isoforms consisting of either $\alpha \beta \gamma \varepsilon \gamma \varepsilon \zeta \zeta$ or $\alpha \beta \delta \varepsilon \delta \varepsilon \zeta \zeta$, subunit combinations (Alarcon et al., 1991) affects the overall interpretation of our data. The branching of the CD2 and of the phosphatidylinositol-linked Thy- 1 and $L y-6$ molecules may be indirect and require additional components. dently of the other does not preclude the occurrence of cooperative interactions once coexpressed in the context of a wild-type TCR/CD3 complex. Second, owing to the utilization of IL-2 production as the only functional read out, it is presently impossible to decide if the two modules operate through distinct or redundant intracellular signaling pathways. Note that irrespective of that, our interpretation predicts that uncoupling antigen recognition from signal transduction will require the inactivation of both modules. Third, in our experiments, a number of indepen-

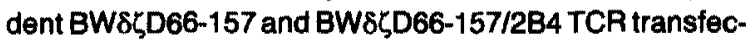
tants were found to be capable of responding to superantigen (SEA) and antigen (PCC $+E^{\mathrm{k}}$ ), respectively. In a previous report, the reconstitution of a $\zeta$-deficient variant of the 2B4 T cell hybridoma with a $\zeta$ construct harboring a truncation of up to $40 \%$ of its cytoplasmic tail ( $\zeta T 108$ ) resulted in the surface expression of TCR/CD3 complexes defective in their ability to respond to both superantigen (SEB) and antigen (PCC + Ek) (Frank et al., 1990). In the absence of data concerning the levels of TCR/CD3 complexes expressed at the level of the 2B4 $\zeta$ T108 transfectants, we have no simple explanation for their impaired antigen responsiveness. However, the lack of stimulation noticed by Frank et al. in response to SEB may be readily accounted for by the recent observation that SEB does not properly stimulate $\mathrm{VB3}^{+} \mathrm{T}$ cells such as the $2 \mathrm{~B} 4 \mathrm{~T}$ cell hybridoma (Gascoigne and Ames, 1991).

The modular structure of the TCR/CD3 complex depicted in Figure 8 also suggests a possible interpretation of the fact that the signals generated through the TCR expressed on immature thymocytes appear partially blunted when compared with mature $T$ cells (reviewed in Finkel ot al., 1991). Considering that $\zeta$ is constitutively phosphorylated in thymocytes (Nakayama et al., 1989; Vivier et al., 1991b), and provided that this modification is a negative regulatory signal (Samelson et al., 1986a), our model suggests that the TCR/CD 3 complexes present on immature $T$ cells express deactivated (phosphorylated) $\zeta$ module. As a consequence, they operate only through the remaining $\gamma \delta \varepsilon$ module and display only part of their signaling ability. In contrast, the TCR/CD3 complexes present on mature $\mathrm{T}$ cells use both modules and trigger more sustained signals and/or connect antigen recognition to a larger range of signaling pathways. Moreover, in view of our finding that the Thy-1 and Ly-6 pathways converge exclusively on the $\zeta$ module, it should be noted that the phosphorylation of $\zeta$ may also affect the operation of these activation pathways during intrathymic development.

Our data also bear on the evolutionary relationships existing between the various subunits involved in the constitution of the TCR, the B cell antigen receptor, and some FcRs. The data reported here for CD8/לD66-114 and our preliminary experiments with a chimera displaying a truncation of the $\zeta$ tail at position 91 indicate that both mutants are still capable of triggering IL-2 production. This led us to suspect the existence of at least two functional domains within the $\zeta$ cytoplasmic tail, and prompted us to analyze the corresponding sequence for the presence of internal repeats. As shown in Figures $5 A$ and 9 , three segments of the $\zeta$ polypeptide, denoted $\zeta \mathrm{a}, \zeta \mathrm{b}$, and $\zeta \mathrm{c}$, and encompassing residues $60-86,99-126$, and $131-156$ may be 


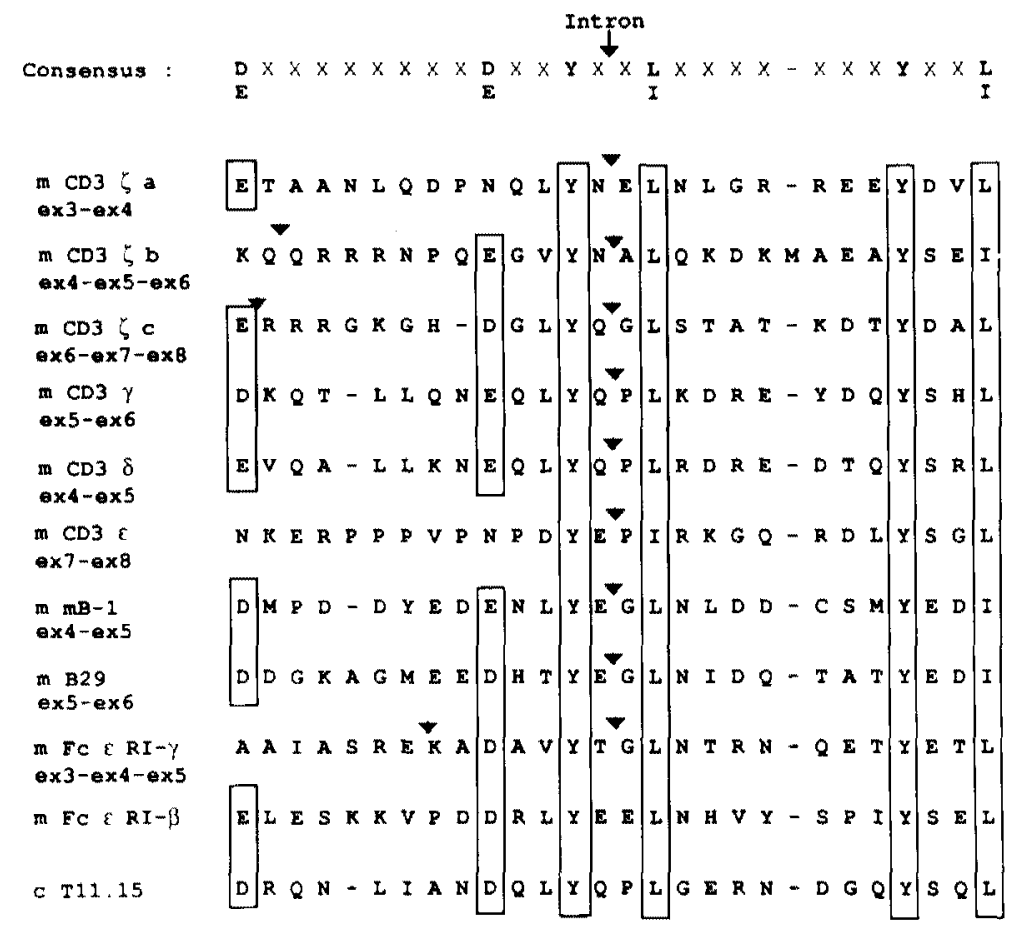

Figure 9. The Cytoplasmic Tail of the CD3- $\zeta$ Polypeptide Chain Contains Three Repeats of the Consensus Sequence D/EX,D/EX ${ }_{2} Y X_{2} L$ $I X_{7} Y X_{2}$ LI Previously Found in the Cytoplasmic Tail of Most of the Polypeptides Associated with Antigen Receptors and FCRs

These three repeats, denoted $\zeta_{a}, \zeta b$, and $\zeta c$, are found at residues 60-86, 99-126, and 139156, respectively. $\zeta c$ corresponds to the motif orginally identified by Reth (1989), and is absent in the CD3- $\eta$ polypeptide. They are compared with the corresponding motifs present in mouse $(m)$ or chicken (c) antigen receptor or FCR chains. Residues identical to the consensus sequence are boxed. Arrows mark the location of the introns in the corresponding genes (see Discussion). Note that there has been some drifting in the position of the introns bordering the extremities of the tabulated motifs (for instance, compare the position of introns 12,14 , and 16 in the $\zeta$ sequence, Figure $5 A$ ). The sequence of the consensus motif found in the chicken $T 11.15$ gene has been indicated since this gene may correspond to a present-day derivative of the common ancestor of the CD3-y and $-\delta$ genes found in mammals. The exonintron organization of the MFceRl- $\beta$ and cT11.15 genes is not known. Gaps are represented as dashes. Sequences are shown in the single-letter amino acid code and referenced in the Experimental Procedures.

aligned by means of six, mostly conserved amino acids. These conserved residues are separated by more variable amino acids and correspond to the framework of a consensus sequence previously found expressed as a single copy in the cytoplasmic tails of various antigen receptor and FCR subunits (see Figure 9 and Reth, 1989). Therefore, the $\zeta$ polypeptide appears to be unique among this set of proteins in the sense that it is the only one to display more than one copy of this motif. Furthermore, preservation of the integrity of only 1 out of the 3 copies, such as in the CD8/לD66-114 or CD8/לT91 mutants, appears sufficient to couple to IL-2 production. However, note that when compared with the CD8/5 molecule, both the CD8/לD66-114 and CD8/לT91 mutants show a two-log shift in their ability to respond to anti-CD8 MAb. Regardless of this decreased competence, probably due to the existence of additive or cooperative effects when the three motifs are expressed together, these data suggest that each of the motifs found in the $\zeta$ cytoplasmic tail may indeed correspond to a discrete functional domain. By inference, the functional capacity of the $\gamma \delta \varepsilon$ module (this paper) and FceRI receptor (Romeo and Seed, 1991; Benhamou et al., 1990) may probably be accounted for by the single-copy motifs expressed within their respective intracellular portions.

Finally, the analysis of the exon-intron organization of the $\zeta$ gene (Baniyash et al., 1989) reveals that each individualized motif straddles the boundary of two exons (exons 3 and 4 for $\zeta a, 5$ and 6 for $\zeta b, 7$ and 8 for $\zeta c$; Figures $5 \mathrm{~A}$ and 9 ), and suggests that these three repeated motifs are probably the result of a triplication of an ancestral pair of exons. Two points support this view. First, the $\zeta a, \zeta b$, and $\zeta c$ coding sequences are interrupted at the very same posi- tion by introns 3,5 , and 7 , respectively ( $33, i 5$, and $i 7$, Figure 5A). Second, in marked contrast to intron 1 , which flanks the $3^{\prime}$ border of the leader coding sequences, and corresponds to a class I intron, all the introns splitting the sequences corresponding to the $\zeta$ cytoplasmic tail (i2 to i7, Figure $5 A$ ) belong to class $O$ introns (classification according to Sharp, 1981). Interestingly, a similar exonintron coding strategy is also found in all the gene segments displaying this consensus motif (Figure 9). Therefore, the molecules harboring these distinctive structural features are probably all evolutionarily related, a possibility that extends considerably the evolutionary relationships previously established between a few of them (e.g., CD3- $\gamma$, $-\delta$, and $-\varepsilon$ [Gold et al., 1987]; CD3- $\zeta$ and FceRI- $\gamma$ [Küster et al., 1990]). Moreover, these observations suggest a tentative evolutionary pathway in which most of the transducing subunits found in antigen receptors and some FcRs stem from a common primordial building block made of two exons, the product of which constituted a functional domain endowed with intracellular signaling properties. In the process of evolution, this primordial domain-encoding segment has undergone multiple rounds of duplication and transposition and has been subjected to triplication $(\zeta)$ or apposed, through exon shuffling, to various Ig-like (B29, $\mathrm{mb}-1, \mathrm{CD} 3-\gamma,-\delta$, and $-\varepsilon$ ) or non-lg-like (FcERI- $\beta$ ) flanking domains. The resulting present-day products are found associated in multisubunit complexes with polypeptides, most of which display a ligend-binding extracellular domain belonging to the immunoglobulin superfamily (e.g., TCR $\alpha \beta$, TCR $\gamma \delta$, membrane IgD or IgM, FcyRIII- $\alpha$, Fc\&RI$\alpha)$. This probable evolutionary relationship may find some functional correspondence in that all the receptors built 
from these subunits have the capacity to activate signaling pathways operated by PTKs (Samelson et al., 1986b; Benhamou et al., 1990; O'Shea et al., 1991; Reth et al., 1991; Vivier et al., 1991a).

\section{Experimental Procedures}

\section{Cells}

BW5147 is an AKR/J-derived thymoma (Hyman and Stallings, 1974). BW5147 $\alpha^{-} \beta^{-}$is a variant of BW5147 lacking functional TCR $\alpha$ and $B$ chain genes (White et al., 1989).

\section{Construction of Plasmids \\ pHAAPr-his}

The vector pHBAPr-his was designed to both express the various CD3- $\zeta$ CDNA constructs under the control of the human $\beta$-actin promoter and select stable T cell transfectants in the presence of histidinot. To construct pH $\beta A P r-h i s$, an EcoPl-BamHI fragment containing the human $\beta$-actin promoter was isolated from plasmid $\mathrm{pH} \beta \mathrm{APP}-1-\mathrm{n} \theta 0$ (Gunning et al., 1987) and subcloned into the EcoRI-BamHI open plasmid pSV2-his (Hartman and Mulligan, 1988).

$\zeta$

The wild-type CD3- $\zeta$ CDNA was excised from plasmid pGEM3 (Weissman et al., 1988) as a $1.2 \mathrm{~kb}$ EcoRl fragment and cloned after filling in the staggered ends into the BamHI-Hindlll blunted sites of plasmid pHBAPr-his. From the resulting clones, plasmid pCA262 ( $\zeta_{1}$ Figure 5A) showed the correct orientation and was selected for transfection.

\section{కD66.114}

To make the deletion mutant $\zeta D 66-114$, the wild-type $\zeta$ CDNA was digested with Pstl. After religation, a plasmid, in which two noncontiguous Pstl fragments (corresponding to nucleotide positions 299-446 and 919-1191; Weissman et al., 1988) have been lost, was selected. In the latter plasmid, the resulting $\zeta$ coding sequence goes in frame and should direct, once cloned into pHBAPr-his, the synthesis of a

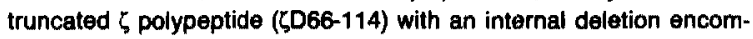
passing amino acids 66 to 114 (plasmid pCA263, Figure 5A).

కD66-157

The construction of the deletion mutant $\zeta \mathrm{D} 66-157$ involved several steps. First, to creale unique restriction sites, a Ndel-Sphl fragment (nucleotide positions 572-1191) was excised from the wild-type $\zeta$ CDNA and cloned, after filling in the Ndel staggered end into the Hindlll-blunted Sphl sites of plasmid pGEM3 (Promega Biotec). The resulting plasmid was denoted pCAC3. Second, the wild-type $\zeta$ CDNA cloned in pGEM3 was digested to completion with Pstl and religated on itself. In the resulting plasmid, denoted PCACB, the $\zeta$ coding sequences 5 ' to the Pstl site located at nucleotide position 299 have been brought in contiguity to the sequences flanking the $P$ stl site present in the pGEM3 polylinker. Finally, plasmid pCA264 was constructed by inserting into the Hindlll-blunted BamHI sites of plasmid PHBAPr-his, an EcoRl-blunted Hindlll fragment isolated from plasmid PCAC8 together with a Hind III-BamHI fragment isolated from plasmid PCAC3. This process resulted in an insertion of $18 \mathrm{bp}$, originating from either the pGEM3 polylinker or the blunted Ndel and Hindlll sites and leaving the truncated $\zeta$ coding sequence in frame. Expression of pCA264 results in the synthesis of a mutant $\zeta$ polypeptide (לD66-157) in which amino acids 66-157 have been deleted and replaced by the sequence QACKL (Figure 5A). The predicted nucleotide sequence of the truncated cytoplasmic tail has been confirmed by DNA sequencing. $\delta$

Plasmid pCA230 ( $\delta$ ) containing the entire wild-type CD3- $\delta$ gene was constructed by inserting a $17 \mathrm{~kb}$ Sall fragment from the $\lambda$ phage genomic clone 13-BM3.3 (Letourneur et al., 1989) into the unique Sall site of plasmid pSV2-gpt (BamHI) Sall. In this construct, the $\delta$ gene retained 9.8 and $2.3 \mathrm{~kb}$ of $5^{\prime}$ and $3^{\prime}$ flanking sequences, respectively.

CDAK, CDQKDE6-114, and CDE/CD66-157

\section{Chimeric Constructions}

PCR was used to amplify a segment of a mouse CD8a CDNA clone (Zamoyska et al., 1985) corresponding to the extracellular domain of the CDBa polypeptide and a segment of the $\zeta$ cDNA clone (Weissman et al., 1988) coding for the transmembrane and cytoplasmic portion of the mouse $\mathrm{CD} 3-\zeta$ polypeptide (see Figure 5B). Similar amplification reactions were also performed using the ${ }^{2} D 66-114$ and $\zeta D 66-157$ cDNAs (see above) as templates. Primers encoding the $3^{\prime}$ sequences of the CD8 fragment and the $5^{\prime}$ sequences of the various $\zeta$ fragments were designed to overlap, such that annealing of each pair of products yielded a hybrid template. From these templates, the various CD8/C chimeric constructs were amplified using external primers containing restriction sites compatible with the ones present in the expression vector pHBAPr.1-neo. Each of the chimeric constructions was sequenced using the dideoxy chain termination method and subsequently subcloned in the $\mathrm{PH} \beta A \mathrm{PP}-1$-neo vector. The native CD $8 \alpha$ chain cDNA was expressed after cloning in the vector PHBAPr-1-neo. $2 B 4$ TCR

The entire $284 \beta$ chain gene was isolated as a $8.3 \mathrm{~kb}$ BamHI genomic fragment (Saito et al., 1987) and cloned after filling in the extremities into the blunted Clal site of plasmid pHBAPr-1-neo/2B $4 \alpha$ (RI) Clal. The latter plasmid was constructed by inserting Clal linkers at the ECORI site bordering the neor gene of plasmid pHBAPr-1-neo/2B4 a (Engel and Hedrick, 1988).

\section{RNA PCR Amplification}

Total RNA was isolated from T cell transfectants according to Chomczinski and Sacchi (1987). Conversion to CDNA and PCR amplification were done as described in Bill et al. (1989). The PCR oligonucleotide primers used in these experiments were: CD8/לc, 5'-AGGGGACCGGATTGGACTTCGATCCCAAACTCTGCTACTT-3; ;d, 5'-ATAAGCTTGCCAGAAGACCCAAGAGCAGGG- 3 '.

The amplified products were analyzed on a $1.7 \%$ agarose gel. Transfer to nitrocellulose and hybridization procedures were per. formed as previously described (Malissen ot al., 1988).

\section{Northern Blot Analysis}

Northern blot analysis was performed as previously described (Letourneur and Malissen, 1989). Hybridization probes were isolated from cDNA clones corresponding to CD3- $\delta$ (clone pSVE- $\delta \mathrm{m}$; Berkhout et al., 1988), CD3-E (clone PSVL-em; Berkhout et al., 1988), and CD3-5

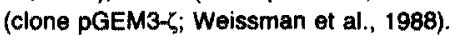

\section{Transfection by Protoplast Fusion}

Transfections of hybridomas with protoplasts and selection in the presence of mycophenolic acid or G418-sulfate were performed as described (Letourneur and Malissen, 1989). For selection in the presence of histidinol, transfected cells were cultured at $1 \times 10^{5}$ cells per well in 96-well tissue culture plates. Selective medium containing $2.5 \mathrm{mM}$ histidinol was applied after $24 \mathrm{hr}$.

\section{Surfase Labeling, Immunopreclpitation, and} SDS-Pclyacrylamide Col Electrophoresis Analysis

Surface iodination of cells was performed according to Goding (1986). Labeled cells were lysed in a lysis buffer containing $0.5 \%$ Triton $X-100$, $300 \mathrm{mM} \mathrm{NaCl}, 50 \mathrm{mM}$ Tris $-\mathrm{HCl}$ (pH 7.6), and $10 \mathrm{mM}$ iodoacetamide (Samelson et al., 1985). Immunoprecipitations were performed with the indicated monoclonal antibodies adsorbed to protein A-Sepharose. Anti-CD3 immunoprecipitates were analyzed in 2D diagonal gels (Goding, 1986) using $10 \%$ acrylamide gels in the first dimension (nonreduced) and $12.5 \%$ acrylamide gels in the second dimension (reduced).

\section{Immunoblotting}

Anti-CD3 immunoprecipitates were resolved on a $10 \%$ nonreducing SDS-polyacrylamide gel as described above. The separated proteins were transferred electrophoretically to nitrocellulose and immunoblotted using a rabbit anti- $\zeta$ serum raised against a synthetic peptide corresponding to amino acids 132-144 (Orloff et al., 1989).

\section{Cytofluorometric Analywis and Antlbodies}

Cytofluorometric analysis was performed on a FACS SCAN cytometer as described previously (Letourneur and Malissen, 1989). The following MAbs were used: 145-2C11 (2C11), anti-CD3- $\varepsilon$ (Leo et al., 1987); G7, anti-Thy 1 (Gunther et al., 1984); D7, anti-Ly-6 (Ortega et al., 1986); A2B4-2, anti-2B4 TCR $\alpha$ chain (Samelson et al., 1983); KJ-25, anti-VB3 (Pullen et al., 1988); H139-69.2.1, anti-mouse IgG3 (Labit and Pierres, 1984). Antibodies were purified either on protein A-Sepharose or DEAE ion-exchange chromatography. 


\section{Stimulation of T Cell Transfectants with Antibodles,}

Antigens, or SEA

In all experiments, $0.25 \mathrm{ml}$ microcultures were prepared containing $10^{5}$ responding $T$ cells along with various stimuli. For stimulation with antigen, the various $2 \mathrm{~B} 4$ TCR transfectants were cultured with $10^{6}$ $E^{\mathrm{k}}$-positive $\mathrm{C3H}$ splenocytes either alone or in the presence of $15 \mu \mathrm{M}$ pigeon cytochrome c peptide 88-104. For stimulation with antibodies adsorbed to FcR-positive cells (Mercép et al., 1988), the transfectants were cultured with $5 \times 10^{4} \mathrm{LK}$ cells (Kappler et al., 1982) as a source of FCR-positive cells and varying concentrations of antibodies. For stimulation with antibodies coated on the surface of microtiter wells, wells were precoated with $50 \mu$ l of a phosphate-buffered saline solution containing varying concentrations of purified antibodies. After $2 \mathrm{hr}$ at room temperature and $1 \mathrm{hr}$ at $4^{\circ} \mathrm{C}$, the wells were washed three times with fetal calf serum-containing medium and used. For stimulation with SEA, transfected cells were cultured with either $10^{5} \mathrm{HLA}^{-D R 1^{+} \mathrm{L}}$ cell transfectants (Jacobson et al., 1989) or $10^{5} \mathrm{LK}$ cells along with varying concentrations of SEA (Toxin Technology). In each instance, cultures were for $24 \mathrm{hr}$, at which time the culture supernatants were harvested and assayed for their level of IL-2 (Gillis et al,. 1978).

\section{Amino Acid Sequences}

The references of the sequences shown in Figure 9 are as follows: $m$ CD3- $\zeta$ (Weissman et al., 1988; Baniyash ot al., 1989); $m$ CD3- $\gamma$ (Krissansen et al., 1987; Haser et al., 1987; Clevers et al., 1988a): m CD3- $\delta$ (Van den Elsen et al., 1986); $m$ CD3- $\varepsilon$ (Clevers ot al., 1988b) m mb-1 (Sakaguchi et al., 1988; Kashiwamura et al., 1990); m B29

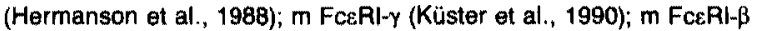
(Ra et al., 1989); and cT11.15 (Bernot and Auffray, 1991).

\section{Acknowledgments}

We thank P. Golstein, J. Cambier, D. Marguet, D. Olive, and A.-M Schmitt-Verhulst for comments on the manuscript and discussion; $J$. Kappler, A. Klausner, P. Marrack, M. Pierres, L. Samelson, and E. Shevach for antibodies; M. Crumpton, R. Germain, S. Hedrick, L. Kedes, M. Malissen, R. C. Mulligan, C. Terhorst, and R. Zamoyska for plasmids; $W$. Born and $E$. Long for cell lines; N. Brun and $M$. Barad for cytofluorometric analysis; $E$. Termine for oligonucleotide synthesis; $J$. Trucy for Southern blot analysis; C. Beziers-La Fosse for graphic art; and V. Preau and N. Chabaud for typing the manuscript. This work was supported by institutional grants from CNRS, INSERM, and specific grants from ARC, FRM, and FEGEFLUC. A.-M. K. W. is supported by a fellowship from the Carlsberg Foundation, F. L. and A. H. by a fellowship from ARC, and T. B. by a Boehringer fellowship.

The costs of publication of this article were defrayed in part by the payment of page charges. This article must therefore be hereby marked "advertisement" in accordance with 18 USC Section 1734 solely to indicate this fact.

Received September 9, 1991; revised October 17, 1991.

\section{Reterences}

Alarcon, B., Ley, S. C., Sanchez-Madrid, F., Blumberg, R. S., Ju, $S$. T., Fresno, $M_{4}$ and Terhorst, C. (1991). The CD3- $\gamma$ and CD3- $\delta$ subunits of the $T$ cell antigen receptor can be expressed within distinct functional TCR/CD3 complexes. EMBO J. 10, 903-912.

Anderson, P., Caligiuri, M., Ritz, J., and Schlossman, S. F. (1989) CD3-negative natural killer cells express $\zeta$ as part of a novel molecular complex. Nature 341, 159-162.

Baniyash, M., Hsu, V. W., Seldin, M. F., and Klausner, R. D. (1989). The isolation and characterization of the murine $T$ cell antigen receptor $\zeta$ chain gene. J. Biol. Chem. 264, 13252-13257.

Bauer, A., McConkey, D. J., Howard, F. D., Clayton, L. L., Novick, D., Koyasu, S., and Peinherz, E. L. (1991). Differential signal transduction via T-cell receptor CD3- $\zeta_{2}, \mathrm{CD} 3-\zeta_{-}-\eta$ and $\mathrm{CD} 3-\eta_{2}$ isoforms. Proc. Natl. Acad. Sci. USA 88, 3842-3846.

Benhamou, M., Gutkind, J. S., Robbins, K. C., and Siraganian, R. P. (1990). Tyrosine phosphorylation coupled to $\mathrm{lgE}$ receptor-mediated signal transduction and histarnine release. Proc. Natl. Acad. Sci. USA 87, 5327-5330.

Berkhout, B., Alarcon, B., and Terhorst, C. (1988). Transfection of genes encoding the $\mathrm{T}$ cell receptor associated CD3 complex into COS cells results in assembly of the macromolecular structure. J. Biol. Chem. 17, 8528-8536.

Bernot, A., and Auffray, C. (1991). Primary structure and ontogeny of an avian CD3 transcript. Proc. Natl. Acad. Sci. USA 88, 2550-2554. Bill, J., Yague, J., Appel, V. B., White, J., Horn, G., Erlich, H. A., and Palmer, E. (1989). Molecular genetic analysis of 178 I-A bm 12 reactive T cells. J. Exp. Med. 169, 115-133.

Blank, U., Ra, C., Miller, L., White, K., Metzger, H., and Kinet, J. P (1989). Complete structure and expression in transfected cells of high affinity lgE receptor. Nature 337, 187-189.

Blumberg, A. S., Lay, S., Sancho, J., Lonberg, N., Lacy, E., McDermott, F., Schad, V., Greenstein, J. L., and Terhorst, C. (1990). Structure of the T-cell antigen receptor: evidence for two CD3 $\varepsilon$ subunits in the T-cell receptor-CD3 complex. Proc. Natl. Acad. Sci. USA 87, 72207224.

Bonifacino, J. S., Chen, C., Lippincott-Schwartz, J., Ashwell, J. D., and Klausner, R. D. (1988), Subunit interactions within the T-cell antigen receptor: clues from the study of partial complexes. Proc. Natl. Acad. Sci. USA 85, 6929-6933.

Bonifacino, J. S., Suzuki, C. K., Lippincott-Schwartz, J., Weissman, A. M., and Klausner, R. D. (1989). Pre-Golgi degradation of newly synthesized T-cell antigen receptor chains: intrinsic sensitivity and the role of subunit assembly. J. Cell Biol. 109, 73-83.

Cantrell, D. A., Davies, A. A., and Crumpton, M. J. (1985). Activators of protein kinase $C$ down-regulate and phosphorylate the $T 3 / T$ cell antigen receptor complex of human T lymphocytes. Proc. Natl. Acad. Sci. USA 82, 8158-8161.

Chomczinski, P., and Sacchi, N. (1987). Single-step method of RNA isolation by acid guanidium thiocyanate-phenol-chloroform extraction. Anal. Blochem. 162, 156-159.

Clayton, L. K., D'Adamio, L., Howard, F. D., Sieh, M., Hussey, R.,

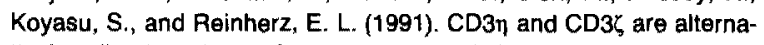
tively spliced products of a common genetic locus and are transcriptionally and/or post-transcriptionally regulated during T-cell development. Proc. Natl. Acad. Sci. USA 88, 5202-5206.

Clevers, H., Alarcon, B., Wileman, T., and Terhorst, C. (1988a). The $T$ cell receptor/CD3 complex: a dynamic protein ensemble. Annu. Rev. Immunol. 6, 629-662.

Clevers, H., Dunlap, S., Saito, H., Georgopoulos, K., Wileman, T., and Terhorst, C. (1988b). Characterization and expression of the murine CD3- $\varepsilon$ gene. Proc. Natl. Acad. Sci. USA 85, 8623-8627.

Cosson, P., Lankford, S. P., Bonifacino, J. S., and Klausner, R. D. (1991). Membrane protein association by potential intramembrane charge pairs. Nature 351, 414-416.

De la Herra, A., Müller, U., Olsson, C., Isaaz, S., and Tunnacliffe. A. (1991). Structure of the $T$ cell antigen receptor (TCR): two CD3E subunits in a functional TCR/CD3 complex. J. Exp. Med. 173, 7-17.

Downward, J., Graves, J. D., Warne, P. H., Rayter, S., and Cantrell, D. A. (1990). Stimulation of p21 upon T-cell activation. Nature 346 719-723.

Engel, I., and Hedrick, S. M. (1988). Site-directed mutations in the VDJ junctional region of a $T$ cell receptor $\beta$ chain cause changes in antigenic peptide recognition. Cell 54, 473-484.

Finkel, T. H., Kubo, R. T., and Cambier, J. C. (1991). T-cell development and transmembrane signaling: changing biological responses through an unchanging receptor. Immunol. Today 12, 79-85.

Frank, S. J., Niklinska, B. B., Orloff, D. G., Mercép, M., Ashwell, J. D., and Klausner, R. D. (1990). Structural mutations of the T cell receptor $\zeta$ chain and its role in T cell activation. Science 249, 174-177.

Gascoigne, N. A. J, and Ames, K. T. (1991). Direct binding of secreted T-cell receptor $\beta$ chain to superantigen associated with class II major histocompatibility complex protein. Proc. Natl. Acad. Sci. USA 88, 613-616.

Gillis, S., Ferm, M. M., Ou, W., and Smith, K. (1978). T cell growth 
factor: parameters of production and a quantitative microassay for activity. J. Immunol. 120, 2027-2032.

Goding, J. W. (1986). Membrane and secretory immunoglobulins: structure, biosynthesis, and assembly. In Handbook of Experimental Immunology, Vol. 1, D. M. Weir, ed. (Oxford: Blackwell Scientific Publications), pp. 20.1-20.33.

Gold, D. P., Clevers, H., Alarcon, B., Dunlap, S., Novotny, J., Williams, A., and Terhorst, C. (1987). Evolutionary relationship between the T3 chain of the T-cell receptor complex and the immunoglobulin supergene family. Proc. Natl. Acad. Sci. USA 84, 7649-7653.

Green, M. N. (1991). The semiotics of charge. Nature 351, 349-350. Gunning, P., Leavitt, J., Muscat, G., Sy, N. G., and Kedes, L. (1987). A human $\beta$-actin expression vector system directs high-level accumulation of antisense transcripts. Proc. Natl. Acad. Sci. USA 84, 48314835.

Gunter, K. C., Malek, T. R., and Shevach, E. M. (1984). T cell activating properties of an anti-Thy-1 monoclonal antibody: possible analogy to OKT3/Leu 4. J. Exp. Med. 159, 716-730.

Hartman, S. C., and Mulligan, R. C. (1988). Two dominant-acting selectable markers for gene transfer studies in mammalian cells. Proc. Natl. Acad. Sci. USA 85, 8047-8051.

Haser, W. G., Saito, H., Koyama, T., and Tonegawa, S. (1987). Cloning and sequencing of murine T3 $\gamma$ cDNA from a subtractive cDNA library. J. Exp. Mod. 166, 1186-1191.

Herman, A., Croteau, G., Sekaly, R. P., Kappler, J., and Marrack, P. (1990). HLA-DR alleles differ in their ability to present staphylococcal enterotoxins to T cells. J. Exp. Med. 172, 709-717.

Hermanson, G. G., Eisenberg, D., Kincade, P. W., and Wall, R. (1988). B29: a member of the immunoglobulin gene superfamily exclusively expressed on B-lineage cells. Proc. Natt. Acad. Sci. USA 85, 68906894.

Hyman, R., and Stallings, V. (1974). Complementation patterns of Thy-1 variants and evidence that antigen loss variants "pre-exist" in the parental population. J. Natl. Cancer Inst. 52, 429-437.

Irving, B. A., and Weiss, A. (1991). The cytoplasmic domain of the $T$ cell receptor $\zeta$ chain is sufficient to couple to receptor-associated signal transduction pathways. Cell 64, 891-901.

Jacobson, S., Sekaly, R. P., Jacobson, C. L., McFarland, H. E., and Long, E. (1989). HLA class II restricted presentation of cytoplasmic measies virus antigens to cytotoxic $T$ cells. J. Virol. 63, 1756-1764. Jin, Y. J., Clayton, L. K., Howard, F. D., Koyasu, S., Sieh, M., Steinbrich, R., Tarr, G. E., and Reinherz, E. L. (1990). Molecular cloning of the $\mathrm{CO} 3$ s subunit identifies a CD35-related product in thymusderived cells. Proc. Natl. Acad. Sci. USA 87, 3319-3323.

June, C. H., Fletcher, M. C., Ledbetter, J. A., Schiever, G. L., Siegel, J. N., Phillips, A. F., and Samelson, L. E. (1990). Inhibition of tyrosine phosphorylation prevents T-cell receptor-mediated signal transduction. Proc. Natl. Acad. Sci. USA 87, 7722-7726.

Kappler, J., White, J., Wegmann, D., Mustain, E., and Marrack, P. (1982). Antigen presentation by la ${ }^{+} B$ cell hybridomas to $\mathrm{H}-2$ restricted T cell hybridomas. Proc. Natt. Acad. Sci. USA 79, 3604-3607.

Kashiwamura, S.-1., Koyama, T., Matsuo, T., Steinmetz, M., Kimoto, M., and Sakaguchi, N. (1990). Structure of the murine mb-1 gene encoding a putative slgM-associated molecule. J. Immunol. 145, 337343

Klausner, R. D., and Samelson, L. E. (1991). T cell antigen receptor activation pathways: the tyrosine kirrase connection. Cell 64, 875-878.

Koning, F., Maloy, W. L., and Coligan, J. E. (1990). The implication of subunit interactions for the structure of the $T$ cell receptor-CD3 complex. Eur. J. Immunol. 20, 299-305.

Krissansen, G. W., Owen, M. J., Fink, P., and Crumpton, M. J. (1987) Molecular cloning of the CDNA encoding the T3y subunit of the mouse T3/T cell antigen receptor complex. J. Immunol. 138, 3513-3518.

Küster, H., Thompson, H., and Kinet, J. P. (1990). Characterization and expression of the gene for the human $\mathrm{FC}$ receptor $y$ subunit. J. Biol. Chem. 265, 6448-6452.

Labit, C., and Pierres, M. (1984). Rat monoclonal antibodies to mouse
IgG1, IgG2a, IgG2b and IgG3 subclasses, and kappa chain isotypic determinants. Hybridoma 3, 163-169.

Lanier, L. L., YU, G., and Phillips, J. H. (1989). Co-association of CD3- $\zeta$ with a receptor (CD16) for igG Fc on human natural killer cells. Nature 342, 803-805.

Leo, O., Foo, M., Sachs, D. H., Samelson, L. E., and Bluestone, J. A. (1987). Identification of a monoclonal antibody specific for a murine T3 polypeptide. Proc. Natl. Acad. Sci. USA 84, 1374-1378.

Letourneur, F., and Malissen, B. (1989). Derivation of a T cell hybridoma variant deprived of functional T cell receptor $\alpha$ and $\beta$ chain transcripts reveals a nonfunctional $\alpha$-mRNA of $8 W 5147$ origin. Eur. J. Immunal. 19, 2269-2274.

Letourneur, F., Mattei, M. G., and Malissen, B. (1989). The mouse CD3- $\gamma,-\delta$ and $-\varepsilon$ genes reside within $50 \mathrm{~kb}$ on chromosome 9 , whereas

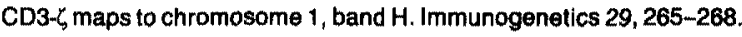
Malissen, M., Trucy, J., Letourneur, F., Rebair, N., Dunn, D. E., Fitch, F. W., Hood, L., and Malissen, B. (1988). A T cell clone expresses two $T$ cell receptor $\alpha$ genes but uses one $\alpha \beta$ heterodimer for allorecognition and self MHC-restricted antigen recognition. Cell 55, 49-59.

Manolios, N., Letourneur, F., Bonifacino, J. S., and Klausner, R. D. (1991). Pairwise, cooperative and inhibitory interactions describe the assembly and probable structure of the T-cell antigen receptor. EMBO J. 10, 1643-1651.

Mercép, M. Bluestone, J. A., Noguchi, P. D., and Ashwell, J. D. (1988). Inhibition of transformed $T$ cell growth in vitro by monoclonal antibodies directed against distinct activating molecules. J. Immunol. 140, 324335.

Mustelin, T., Coggeshall, K. M., Isakov, N., and Altman, A. (1990). T cell antigen receptor-mediated activation of phospholipase $C$ requires tyrosine phosphorylation. Science 247, 1584-1587.

Nakayama, T., Springer, A., Hsi, E. D., and Samelson, L. E. (1989). Intrathymic signalling in immature $\mathrm{CO}^{+} \mathrm{CDB}^{+}$thymocytes results in tyrosine phosphorylation of the TCR $\zeta$ chain. Nature 341, 651-654.

Orloff, D. G., Frank, S. J., Robey, F. A., Weissman, A. M., and Klausner, R. D. (1989). Biochemical characterization of the $\eta$ chain of the T cell receptor. J. Biol. Chem. 264, 14812-14817.

Orloff, D. G., Ra, C., Frank, S. J., Klausner, R. D., and Kinet, J. P. (1990). Family of disulphide-linked dimers containing the $\zeta$ and $\eta$ chains of the $T$-cell receptor and the $y$ chain of the $F c$ receptors. Nature $347,189-191$

Ortega, G., Korty, P. E., Shevach, E. M., and Malek, T. F. (1986). Role of $L y-6$ in lymphocyte activation. I. Characterization of a monoclonal antibody to a nonpolymorphic Ly-6 specificity. J. Immunol. 137, 32403246.

O'Shea, J. J., Weissman, A. M., Kennedy, I. C. S., and Ortaldo, J. R. (1991). Engagement of the natural killer cell ig G Fc receptor results in tyrosine phosphorylation of the $\zeta$ chain. Proc. Natl. Acad. Sci. USA 88, 350-354.

Park, D. J., Rho, H. W., and Rhee, S. G. (1991). CD3 stimulation causes phosphorylation of phospholipase C-y1 on serine and tyrosine residues in a human T cell line. Proc. Natt. Acad. Sci. USA 88, 54535456.

Pullen, A. M., Marrack, P., and Kappler, J. W. (1988). The T cell reper toire is heavily influenced by tolerance to polymorphic self-entigens. Nature 335, 796-801.

Ra, C., Jouvin, M.-E., and Kinet, J.-P. (1989). Complete structure of the mouse mast cell receptor for $\mathrm{IgE}$ (FceRl) and surface expression of chimeric receptors on transfected cells. J. Biol. Chem. 264, 1532315327.

Reth, M. (1989). Antigen receptor tail clue. Nature 338, 383-384.

Reth, M., Hombach, J., Wienands, J., Campbell, K. S., Chien, N., Justement, L. B., and Cambier, J. C. (1991). The B-cell antigen receptor complex. Immunol. Today 12, 196-201.

Romeo, C., and Seed, B. (1991). Cellular immunity to HIV activated by CD4 fused to $T$ cell or $F c$ receptor polypeptides. Cell 64, 1037-1046. Saito, T., Weiss, A., Miller, J., Norcross, M. A., and Germain, R. (1987). Specific antigen-la activation of transfected human $T$ cells expressing murine Ti $\alpha \beta$-human T3 receptor complexes. Natures 325, 125-130. 
Sakaguchi, N., Kashiwamura, S., Kimoto, M., Thalmann, P., and Melchers, F. (1988). B lymphocyte lineage-restricted expression of mb-1, a gene with CD3-like structural properties. EMBO J. 7, 34573464.

Samelson, L. E., Germain, R. N., and Schwartz, R. H. (1983). Monoclonal antibodies against the antigen receptor on a cloned T-cell hybrid. Proc. Natl. Acad. Sci. USA 80, 6972-6976.

Samelson, L. E., Harford, J. B., and Klausner, R. D. (1985). Identification of the components of the murine $\mathrm{T}$ cell antigen receptor complex. Cell 43, 223-231.

Samelson, L. E., Davidson, W. F., Morse, H. C., and Klausner, P. D. (1986a). Abnormal tyrosine phosphorylation on T-cell receptor in lymphoproflierative disorders. Nature 324, 674-676.

Samelson, L. E., Patel, M. D., Weissman, A. M., Harford, J. B., and Klausner, R. D. (1986b). Antigen activation of murine T cells induces tyrosine phosphorylation of a polypeptide associated with the $T$ cell antigen receptor. Cell 46, 1083-1090.

Sharp, P. A. (1981). Speculations on RNA splicing. Cell 23, 643-646. Siegel, J. N., Klausner, R. D., Rapp, U. R., and Samelson, L. E. (1990). $T$ cell receptor engagement stimulates $c$-raf phosphorylation and induces c-raf-associated kinase activity via a protein-kinase C-dependent pathway. J. Biol. Chem. 265, 18472-18480.

Sussman, J. J., Saito, T., Shevach, E. M., Germain, R. N., and Ashwell, J. D. (1988). Thy-1 and Ly-6 mediated lymphokine production and growth inhibition of a $T$ cell hybridoma require co-expression of the $T$ cell antigen receptor complex. J. Immunol. 140, 2520-2526.

Van den Elsen, P., Georgopoulos, K., Shepley, B. A., Orkin, S., and Terhorst, C. (1986). Exon/intron organization of the genes coding for the $\delta$ chains of the human and murine T-cell receptor $T 3$ complex. Proc. Natl. Acad. Sci. USA 83, 2944-2948.

Vivier, E., Morin, P., O'Brien, C., Drukker, B., Schlossman, S. F., and Anderson, P. (1991a). Tyrosine phosphorylation of the FCy R III (CD16): $\zeta$ complex in human natural killer cells. J. Immunol. 146, 206-210.

Vivier, E., Morin, P., Tian, Q., Dalay, J., Blue, M.-L., Schlossman, S.F., and Anderson, P. (1991b). Expression and tyrosine phosphorylation of the $T$ cell receptor $\zeta$-subunit in human thymocytes. J. Immunol. 146, 1142-1148.

Weiss, A., Koretsky, G., Schatzman, R., and Kadlecek, T. (1991). Functional activation of the T-cell antigen receptor induces tyrosine phosphorylation of phospholipase C- $\gamma 1$. Proc. Natl. Acad. Sci. USA 88, 5484-5488.

Weissman, A. M., Baniyash, M., Hou, D., Samelson, L. E., Burgess, W. H., and Klausner, R. D. (1988). Molecular cloning of the zeta chain of the $T$ cell antigen receptor. Science 239, 1018-1021.

White, J., Blackman, M., Bill, J., Kappler, J., Marrack, P., Gold, D., and Born, W. (1989). Two better cell lines for making hybridomas expressing specific T cell receptors. J. Immunol. 143, 1822-1825.

Zamoyska, R., Vollmer, A. C., Sizer, K. C., Liaw, C. W., and Parnes, J. R. (1985). Two Lyt-2 polypeptides arise from a single gene by alternative splicing patterns of mRNA. Cell 43, 153-163. 